\title{
1 The interferon-inducible GTPase MxB promotes capsid disassembly 2 and genome release of herpesviruses
}

3

4 Manutea C. Serrero ${ }^{1,2}$, Virginie Girault ${ }^{3}$, Sebastian Weigang ${ }^{4}$, Todd M. Greco ${ }^{5}$,

5 Ana Ramos-Nascimento ${ }^{1}$, Fenja Anderson ${ }^{1}$, Antonio Piras $^{3}$, Ana Hickford Martinez $^{1}$,

${ }^{1}$ Institute of Virology, Hannover Medical School, Hannover, Germany

${ }^{2}$ RESIST - Cluster of Excellence, Hannover Medical School, Hannover, Germany

${ }^{3}$ Institute of Virology, Technical University Munich, Munich, Germany

${ }^{4}$ Institute of Virology, Freiburg University Medical Center, University of Freiburg, Freiburg, Germany

${ }^{5}$ Department of Molecular Biology, Princeton University, Princeton, USA

${ }^{6}$ MRC Human Immunology Unit, MRC Weatherall Institute of Molecular Medicine, Radcliffe Department of Medicine, University of Oxford, Oxford, UK

${ }^{7}$ German Center for Infection Research (DZIF), Hannover-Braunschweig Partner Site, Germany

${ }^{8}$ Research Core Unit Laser Microscopy, Hannover Medical School, Hannover, Germany

${ }^{9}$ German Center for Infection Research (DZIF), Munich Partner site, Germany

Corresponding author:

Beate Sodeik

Institute of Virology, OE 5230

Hannover Medical School

Carl-Neuberg-Str. 1, D-30623 Hannover, Germany

Phone: ++49 - 511 - 5322846

FAX: $\quad++49-511-5328736$

Email: sodeik.beate@mh-hannover.de

Number of pages:

47

Number of figures:

8 figures, 8 supplementary figures, 4 supplementary tables 


\section{$34 \quad$ ABSTRACT}

Host proteins sense viral products and induce defence mechanisms, particularly in immune cells.

Using cell-free assays and quantitative mass spectrometry, we determined the interactome of capsid-

37 host protein complexes of herpes simplex virus and identified the large dynamin-like GTPase myxovirus resistance protein $\mathrm{B}(\mathrm{MxB})$ as an interferon-inducible protein interacting with capsids. Electron microscopy analyses showed that cytosols containing MxB had the remarkable capability to disassemble the icosahedral capsids of herpes simplex viruses and varicella zoster virus into flat

41 sheets of connected triangular faces. In contrast, capsids remained intact in cytosols with MxB

42 mutants unable to hydrolyse GTP or to dimerize. Our data suggest that MxB senses herpesviral 43 capsids, mediates their disassembly, and thereby restricts the efficiency of nuclear targeting of incoming capsids and/or the assembly of progeny capsids. The resulting premature release of viral genomes from capsids may enhance the activation of DNA sensors, and thereby amplify the innate immune responses. 


\title{
INTRODUCTION
}

\author{
Infections with human alphaherpesviruses are associated with painful and stigmatizing
} manifestations such as herpes labialis or herpes genitalis, but also cause life-threatening meningitis or encephalitis, potentially blinding eye infections, herpes zoster, and post-herpetic neuralgia, particularly in immunocompromised patients (Gershon et al., 2015; Whitley \& Roizman, 2016; Whitley \& Johnston, 2021). Herpes simplex viruses (HSV-1, HSV-2) and varicella zoster virus (VZV) productively infect epithelial and fibroblast cells of the skin and mucous membranes as well as neurons, but are restricted in immune cells. Macrophages, Langerhans cells, dendritic cells, and NK cells mount potent immune responses against alphaherpesviruses (Whitley \& Roizman, 2016).

Intracellular DNA sensors are crucial to sense herpesvirus infections, and to induce caspase-1 mediated inflammation and type I IFN expression (Hertzog \& Rehwinkel, 2020; Kurt-Jones et al., 2017; Lum \& Cristea, 2021, Ma et al., 2018; Paludan et al., 2019; Stempel et al., 2019). During an unperturbed infection, capsid shells shield herpesviral genomes from cytosolic sensors during nuclear targeting as well as after nuclear genome packaging (Arvin \& Abendroth, 2021; Döhner et al., 2021; Knipe et al., 2021). HSV-1 capsids can withstand compressive forces of up to $6 \mathrm{nN}$ which is more than sufficient to endure the 18 atm repulsive pressure of the packaged viral DNA (Bauer et al., 2013; Roos et al., 2009). So far, it is unclear how cytosolic DNA sensors gain access to herpesviral genomes; either cytosolic host factors disassemble the sturdy herpesviral capsids during infection, or the nuclear envelopes become leaky.

HSV-1 virions contain an amorphous tegument layer that links the icosahedral capsids with a diameter of $125 \mathrm{~nm}$ to the viral envelope proteins (Crump, 2018; Dai \& Zhou, 2018; Diefenbach, 2015). To identify cytosolic proteins that promote or restrict infection by interacting with HSV-1 capsids, we have developed cell-free methods to reconstitute capsid-host protein complexes using tegumented capsids from extracellular viral particles or tegument-free capsids from the nuclei of infected cells (Radtke et al., 2014). Intact capsids are incubated with cytosol prepared from tissues or cultured cells, and the capsid-host protein complexes are isolated, and characterized by mass spectrometry (MS), immunoblot, electron microscopy, and functional assays. We could show that 
HSV-1 capsids require inner tegument proteins to recruit microtubule motors, to move along microtubules, to dock at nuclear pore complexes (NPCs), to release viral genomes from capsids, and to import viral genomes into the nucleoplasm, and that capsids lacking tegument cannot move along microtubules, but still bind to nuclear pores (Anderson et al., 2014; Ojala et al., 2000; Radtke et al., 2010; Wolfstein et al., 2006).

Here, we searched for proteins that might contribute to sensing cytosolic capsids and thereby promote the detection of herpesviral genomes. Using extracts of matured THP-1 cells, a model system for human macrophages (Tsuchiya et al., 1980), we identified type I interferon (IFN) inducible proteins that bound specifically to HSV-1 capsids. Among them was the large dynamin-like GTPase myxovirus resistance protein $\mathrm{B}(\mathrm{M} \times \mathrm{B})$. MxB limits the infection of several herpesviruses, and can mediate almost $50 \%$ of the IFN-mediated restriction of HSV-1, although its mode of action has remained elusive so far (Crameri et al., 2018; Liu et al., 2012; Schilling et al., 2018; Vasudevan et al., 2018). MxB has been first described for its potent inhibition of HIV infection (Goujon et al., 2013; Kane et al., 2013; Liu et al., 2013). The human MX2 gene codes for a full-length MxB (residues 1-715) and a smaller version (residues 26-715) that lacks an N-terminal extension (NTE), which both are highly expressed upon IFN induction (Melen et al., 1996). MxB likely operates as an anti-parallel dimer but can also form higher-order filaments; its N-terminal GTPase domain connects to a bundle signalling element that moves relative to the GTPase domain in response to nucleotide binding, and the C-terminal stalk domain is critical for MxB oligomerization (Alvarez et al., 2017; Chen et al., 2017; Fribourgh et al., 2014; Gao et al., 2011).

We show here that both, full-length $\mathrm{MxB}(1-715)$ and $\mathrm{MxB}(26-715)$ have the remarkable property to disassemble the capsids of the three human alphaherpesviruses HSV-1, HSV-2, and VZV, so that they can no longer transport nor shield the viral genomes. Capsid disassembly did not require proteases but depended on the ability of MxB to hydrolyse GTP and to dimerize. As the large tegument protein pUL36 links the capsid vertices to the other tegument proteins (Crump, 2018; Dai \& Zhou, 2018; Diefenbach, 2015), and as an increasing amount of associated tegument proteins protected capsids against $\mathrm{MxB}$ mediated disassembly, we propose that $\mathrm{MxB}$ attacks the capsids at 
their vertices. Our data suggest that $\mathrm{MxB}$ can bind to and disassemble incoming as well as progeny capsids, and thereby might increase the sensing of cytosolic and nuclear viral genomes. Therefore, the MxB GTPase might be the sought-after capsid destroyer that acts upstream of cytosolic or nuclear sensors to promote viral genome detection and induction of innate immune responses.

\section{RESULTS}

IFN induction prevents HSV-1 infection of macrophages. Before investigating capsid interactions with macrophage proteins, we compared HSV-1 infection in human keratinocytes (HaCat), pigment epithelial cells (RPE), and THP-1 cells at low, moderate or high multiplicity of infection (MOI). We stimulated monocyte THP-1 cells with phorbol 12-myristate 13 -acetate to differentiate them into a macrophage-like phenotype, and used them either directly $(M \phi)$ or after a resting period of 3 days $\left(M \phi_{R}\right) . H S V-1$ replicated productively in HaCat and RPE cells up to $20 \mathrm{hpi}$, while a pre-treatment with IFN delayed and reduced but did not prevent the production of infectious virions (Fig. 1). Both M\$ and $M \phi_{R}$ released 10 to 100 -fold less infectious HSV-1, and an IFN pre-treatment prevented infection at all MOls. Thus, $M \phi$ and $M \phi_{R}$ restricted HSV-1 infection efficiently, and the induction of IFNstimulated genes (ISGs) prevented any productive infection.

IFN-induced protein changes in the cytosol of macrophages. To identify cytosolic macrophage proteins that might foster or restrict HSV-1 capsid functions, we prepared extracts from $M \phi_{R}$ or IFNinduced $M \phi_{I F N}$ to reconstitute capsid-host protein complexes as they might assemble in macrophages (Fig. S1). Using subcellular fractionation and subsequent dialysis (Fig. S2A), we depleted the extracts of nuclei and mitochondria (Fig. S2B; pellet P1), cytoplasmic membranes such as Golgi apparatus, endoplasmic reticulum and plasma membrane (P1, P2), and small metabolites (S2, S3, S4). Furthermore, most of the cytoskeletal tubulin and actin sedimented into the first pellet (P1), while glyceraldehyde 3-phosphate dehydrogenase (GAPDH), a bona-fide cytosolic protein, remained soluble in the supernatants ( $\left.\mathrm{S} 1, \mathrm{~S} 2, \mathrm{~S} 2^{\prime}, \mathrm{S} 3, \mathrm{~S} 4\right)$. Next, we analysed the proteomes of the $\mathrm{M} \phi_{\mathrm{R}}$ and IFN-induced $M \Phi_{\text {IFN }}$ cytosols at low ATP/GTP concentration [ATP/GTP ${ }^{\text {low }}$ ] by mass spectrometry (MS; Table S1). We detected 494 (Fig. S2C; black circles) of more than 600 reported IFN-inducible proteins 
127 (Rusinova et al., 2013). Of those, GALM, COL1A1, LGALS3BP, NT5C3A, IFI44, IFIT2, IFIT3, GBP4, SRP9,

128 IFIT5, DSP, and L3HYPDH were enriched by at least 2-fold in the M $\phi_{\text {IFN }}$ cytosol (Fig. S2C; red). These changes might reflect IFN-induced transcriptional or translational regulation, post-translational modification, subcellular localization, or susceptibility to proteolysis, and show that the IFN induction had changed the cytosol proteome of the $M \phi_{\text {IFN }}$.

HSV-1 capsids interact with specific cytosolic macrophage proteins. To search for cytosolic M $\phi$ proteins whose interactions with HSV-1 capsids depend on their surface composition, we generated

tegumented viral $V_{0.1}, V_{0.5}$, and $V_{1}$ capsids as well as $D$ capsids with a reduced tegumentation (Fig.

S1). For this, we lysed extracellular particles released from HSV-1 infected cells with non-ionic detergent to solubilize the envelope proteins and lipids, and in the presence of $0.1,0.5$, or $1 \mathrm{M} \mathrm{KCl}$ to modify intra-tegument protein-protein interactions (Anderson et al., 2014; Ojala et al., 2000; Radtke et al., 2010; Radtke et al., 2014; Wolfstein et al., 2006; Zhang \& McKnight, 1993). Furthermore, we dissociated tegument from $V_{0.1}$ capsids by a limited trypsin digestion to generate so-called $D$ capsids.

We then incubated similar amounts of different capsid types as calibrated by immunoblot for the major capsid protein VP5 (Fig. S2D) with cytosol at ATP/GTP ${ }^{\text {low }}$ from $M \phi_{R}$ or IFN-induced $M \phi_{\text {IFN }}$ for 1

$\mathrm{h}$ at $37^{\circ} \mathrm{C}$. The capsid-host protein complexes assembled in vitro were harvested by sedimentation, and their interactomes were determined by quantitative MS (c.f. Fig. S1). As before (Radtke et al., 2010; Snijder et al., 2017), the protein intensities were normalized across samples to the abundance of the major capsid protein VP5 (Table S2, host; Table S3, viral).

Of 2983 proteins identified (Table S2), we detected 1816 in at least 3 of the 4 replicates in any of the 8 different capsid-host protein complexes. Of those, 598 host proteins bound differentially to one capsid type over another (Table S2; fold change $\geq 2.8$; permutation-based FDR $\leq 0.05$ ). The HSV-1 capsids had recruited specifically 279 proteins of $M \phi_{R}$ and 390 of $M \phi_{\text {IFN }}$ cytosol of which 71 were shared. Hierarchical clustering analyses of the associated $M \phi_{R}$ or $M \phi_{\text {IFN }}$ proteins identified 4 major classes; e.g. one enriched on $\mathrm{V}$ over D capsids (Fig. S3A and S3B, top green) and one enriched on 
(Table S2; difference $\geq 2.83$-fold; FDR $\leq 0.01$ ). The $M \phi_{R}$ capsid-host complexes included 12 and the ones of $M \phi_{\text {IFN }} 19$ proteins listed in the interferome database (Rusinova et al., 2013; red in Fig. 2).

$M \phi_{\text {IFN }}$ (Fig. 3) proteins included many players of innate immunity, intracellular transport, nucleotide suggest that protein domains displayed on different capsids interacted with specific cytosolic $M \phi_{R}$ or M $\phi_{\text {IFN }}$ proteins.

In these assays, the capsids interacted with several proteins already validated to promote or restrict HSV or VZV infection. Examples are the ESCRT-III co-factor VPS4 (Cabrera et al., 2019; Crump et al., 2007), EIF4H (Page \& Read, 2010), the Kif2a subunit of kinesin-13 (Turan et al., 2019), the POLR1C subunit of RNA polymerase III (Carter-Timofte et al., 2018), the DNA protein kinase PRKDC (Justice et al., 2021), and DDX1 (Zhang et al., 2011). Moreover, the deubiquitinase USP7 (Rodriguez et al., 2020) and the ubiquitin ligases RNF123, TRIM72, UFC1 and UBE3A as well as the proteasome might regulate capsid functionality (Huffmaster et al., 2015; Schneider et al., 2021) or their degradation(Horan et al., 2013; Sun et al., 2019). These data show that HSV-1 capsids exposing a different tegument composition recruited specific cytosolic proteins from resting or IFN-induced macrophages.

HSV-1 capsids recruit specific proteins responding to or regulating type I IFN. We next analysed

177 the $M \phi_{\text {IFN }}$ samples in detail as IFN induction had prevented HSV-1 infection completely. We 178 generated cluster maps for the 32 capsid-associated proteins belonging to the GO clusters Response 179 to type I IFN or Regulation of type I IFN production (Table S2). V capsids recruited DHX9, HSPD1 and 
XCCR6 from both, $M \phi_{R}$ and $M \phi_{\text {IFN }}$ cytosol (Fig. 4). Interestingly, $V$ capsids bound specifically to STAT1

in $M \phi_{R}$, but to ADAR and IFIT2 in M $\phi_{\mathrm{IFN}}$ cytosol. D capsids were enriched for IFI16, OAS2, POLR1C, STAT2, and $M \times B$ in $M \phi_{I F N}$ but not in $M \phi_{R}$ (Fig. 4, Fig. S5). Particularly, the discovery of $M \times B$ in these capsid-host protein complexes was interesting, as MxB but not its homolog MxA restricts infections of the herpesviruses HSV-1, HSV-2, MCMV, KSHV, and MHV-68, but its mode of action has not been elucidated (Crameri et al., 2018; Liu et al., 2012; Schilling et al., 2018; Vasudevan et al., 2018). Therefore, we investigated the interaction of human MxB with HSV-1 capsids further. preparation (Fig. S2). As reported (Goujon et al., 2013; Melen et al., 1996), MxB was upregulated in IFN-induced $M \phi_{\text {IFN. }}$ MxB sedimented with nuclei and mitochondria as expected (Cao et al., 2020), with cytoplasmic membranes, and possibly filamentous MxB (Alvarez et al., 2017) might have been sedimented too. Both, after the addition of ATP and GTP (ATP/GTP ${ }^{\text {high }}$ ) or the hydrolase apyrase (Pilla et al., 1996; ATP/GTP ${ }^{\text {low }}$ ), a significant fraction of MxB remained soluble in the cytosol. been incubated in cytosols from $M \phi_{R}$ or $M \phi_{\text {IFN }}$. In line with the MS results, MxB bound better to $D$ than to $V_{0.1}, V_{0.5}$, or $V_{1}$ capsids (Fig. $5 A$ ). We next probed authentic nuclear capsids, namely empty $A$, scaffold-filled $B$, or DNA-filled $C$ capsids, as well as tegumented $V_{1}, V_{0.5}, V_{0.1}$ or $D$ capsids with cytosol of $A 549-\mathrm{MxB}(1-715)$ epithelial cells expressing $\mathrm{MxB}(1-715)$. Nuclear $A$ and $C$ as well as $V_{1}$ and $D$ capsids recruited $M \times B$ efficiently, while $B, V_{0.1}$ and $V_{0.5}$ capsids bound less $M \times B$ (Fig. $5 B$ ). MxB did not sediment by itself, and also did not associate with agarose beads used as another sedimentation control (Fig. 5A, 5B). These data indicate that MxB binds to specific structural features on the capsid surface.

In cells, MxB mediated restriction of herpesvirus replication depends on its $\mathrm{N}$-terminal 25 amino acid residues (NTE), its GTPase activity, and its capacity to form dimers (Crameri et al., 2018; Schilling et al., 2018; Vasudevan et al., 2018). We incubated capsids with cytosols containing MxA, MxB(1715), MxB(26-715) (Melen et al., 1996; Melen \& Julkunen, 1997), MxB(K131A) with reduced GTP 
$\mathrm{MxB}(26-715)$, and $\mathrm{MxB}(\mathrm{M} 574 \mathrm{D})$ co-sedimented with capsids to a similar extent. Interestingly,

$\mathrm{MxB}(\mathrm{K} 131 \mathrm{~A})$ did not bind to capsids, while $\mathrm{MxB}(\mathrm{T} 151 \mathrm{~A})$ bound even stronger (Fig. 5C). These data

suggest that conformational changes associated with GTP binding or hydrolysis contribute to $\mathrm{MxB}$ interaction with HSV-1 capsids.

MxB disassembles capsids of alphaherpesviruses. Next, we tested whether MxB might affect

HSV-1 capsid stability. While the previous capsid sedimentation assays were performed at isolated capsids directly onto EM grids and then placed them on a drop of cytosol to allow the formation of capsid-host protein complexes (Fig. 6A). This direct on-grid assay required 50 times fewer capsids than the sedimentation-resuspension assay and allowed for time-course analyses. For both, we negatively contrasted the samples with uranyl acetate and analysed them by electron microscopy.

When capsids were incubated with cytosol from A549 control cells not containing MxB, we saw mostly intact capsids with an appropriate diameter of about $125 \mathrm{~nm}$, and an intact icosahedral morphology characterized by pentons at the vertices and hexons on the triangular capsid faces

(Fig. 6B). The capsids contained genomic DNA as the uranyl acetate used for negative contrast staining had not or only partially entered the capsid lumen. But a treatment with cytosol from IFN-induced $M \phi_{\text {IFN }}$ or $A 549-M \times B(1-715)$ cells dramatically impaired the capsid shell. Based on different $M \times B$ induced morphological changes, we classified the capsid structures that we had identified by immunolabeling for capsid proteins (Fig. S6) into three categories. Intact capsids 232 (Fig. 6B, Fig. S6A) have an icosahedral morphology and include empty A, scaffold-filled B, and DNA233 filled C capsids. Punched capsids are characterized by indentations on one or more vertices and an 
(Fig. 6D, Fig. S6C). We estimated the number of capsomers on flat shells based on their area, and

scored a structure with $<100$ capsomers as a half capsid and with $\geq 100$ as one capsid (numbers in

Fig. 6D). Cytosols containing MxB(1-715) also disassembled capsids of HSV-2 (not shown) or VZV (Fig.

$6 \mathrm{E})$ to punched capsids and flat shells. As MxB induced capsid disassembly of HSV-1, HSV-2 and VZV,

these experiments suggest that $M \times B$ restricts the infection of herpesviruses by targeting their capsids.

MxB requires GTP hydrolysis and dimerization to attack herpesviral capsids. Next, we further

characterized the capsid disassembly activity of $\mathrm{MxB}$ by quantitative electron microscopy. Cytosol

from IFN-induced $M \phi_{\text {IFN }}$ disassembled more than $80 \%$ of the capsids within $1 \mathrm{~h}$ while resting $M \phi_{R}$

capsids, while cytosol from $\mathrm{A} 549-\mathrm{MxB}(1-715)$ cells disassembled capsids almost as efficiently as

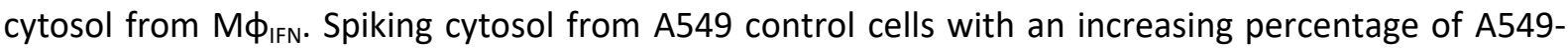

MxB(1-715) cytosol led to an increasing capsid disassembly with a majority of punched capsids, at

$50 \%$ or $66 \% \mathrm{MxB}$ cytosol, while incubation in pure $\mathrm{A} 549-\mathrm{MxB}(1-715)$ cytosol lead to more than $95 \%$ disassembly to mostly flat shells within $1 \mathrm{~h}$ of incubation (Fig. 7B). We then asked whether MxB had activated other host proteins to mediate capsid disassembly, or whether it was directly responsible.

We prepared cytosol from $A 549-M \times B(1-715)-M \times B(26-715)$ expressing both untagged $M \times B$ proteins, or from A549-MxB-FLAG expressing MxB(1-715)-FLAG and MxB(26-715)-FLAG. Both cytosols promoted capsid disassembly (MxB; MxB-FLAG in Fig. 7C), but an immunodepletion with anti-FLAG cytosol (MxB FT).

We next tested at ATP/GTP high the effect of various MxB mutants on HSV-1 capsid stability. While full-length $\mathrm{MxB}(1-715)$ induced capsid disassembly, the $\mathrm{MxB}$ mutants impaired in GTPase activity 260 (T151A), GTP binding (K131A), or dimerization (M574D) as well as cytosol with MxB at ATP/GTPlow did not (Fig. 7D). In contrast, the smaller $\mathrm{MxB}(26-715)$ protein lacking the NTE retained about $50 \%$ of the 

time-course revealed a lag phase of about 30 min until broken capsids appeared with increasing rate shells continued to increase (Fig. 7E). Further experiments showed that MxB attacked D capsids more contrast, the $\mathrm{V}_{0.1}$ capsids seemed to be spared from $\mathrm{MxB}$ attack, since no broken capsids appeared within an $1 \mathrm{~h}$ treatment. Since MxB restricts infection of several herpesviruses (Crameri et al., 2018; Liu et al., 2012; Schilling et al., 2018; Vasudevan et al., 2018), we compared the impact of MxB on D capsids from HSV-1(17')Lox, HSV-1(KOS), HSV-2(333), or on nuclear C capsids from VZV(rOka). Capsids of these human alphaherpesviruses were all susceptible to MxB attack (Fig. 7G). three or two times more viral genomes in cytosols from $\mathrm{MxB}(1-715)$ or MxB-FLAG than from control or MxB(M574D) cells (Fig. 7H). Together, these data indicate that the MxB GTPase disassembles the capsid shells and induces a release of viral DNA of several herpesviruses. Our experiments suggest that GTP binding and hydrolysis as well as dimerization contribute to MxB-mediated disassembly of alphaherpesvirus capsids. Its slow start with a lag of about 30 min indicates that the capsid attack might require some nucleating or cooperative reaction to assemble active $\mathrm{MxB}$ oligomers or an MxB-containing complex onto capsids.

Tegument proteins protect against $\mathbf{M x B}$ attack. As complete tegumentation shielded $\mathrm{V}_{0.1}$ capsids of the 58 HSV-1 proteins detected to the normalized amounts of the major capsid protein VP5. The tegument compositions of $V_{0.1}, V_{0.5}$, and $V_{1}$ capsids were similar to each other but different from $D$ 
the capsid specific vertex components (CSVC) pUL17 and pUL25, and to some extent the portal pUL6, and less of the major tegument proteins VP22, VP13/14, VP16, VP11/12 as well as other tegument proteins with ICPO, pUL36 and pUL37 being most susceptible to the trypsin treatment. Overall, there were little differences in the relative tegument protein amounts among $V_{0.5}$ and $V_{1}$ capsids. In contrast, $\mathrm{V}_{0.1}$ capsids contained more tegument proteins, e.g. VP13/14, pUS3, pUL41, pUL16, pUS11 and pUL40. All capsid preparations contained traces of membrane proteins and nuclear HSV-1 proteins contributing to DNA replication and packaging (Fig. S8). These data further validated that a treatment with 0.5 or $1 \mathrm{M} \mathrm{KCl}$ during the detergent lysis of virions destabilized intra-tegument interactions. Furthermore, the limited trypsin digestion had reduced the capsid proteome further and increased the susceptibility to MxB attack.

\section{DISCUSSION}

Cell-type specific defence mechanisms shape the arms race between proteins restricting or promoting nuclear targeting of incoming viral capsids and viral genome release into the nucleoplasm.

We have developed biochemical assays to investigate functional interactions of viral capsids with host cell structures (Radtke et al., 2014), and analysed here HSV-1 capsid-host protein complexes assembled in cytosols from resting $M \phi_{R}$ or IFN-induced $M \phi_{\text {IFN }}$ cells. We show that the IFN-inducible MxB GTPase bound to alphaherpesviral capsids, most likely to structural features around the capsid vertices, and disassembled herpesvirus capsids in a GTP-dependent fashion, and so that they no longer shielded the viral genomes. Capsid disassembly by MxB could reduce nuclear targeting of incoming capsids and genomes, but stimulate the activation of cytosolic DNA sensors and innate immune responses.

Cytosolic IFN-induced macrophage proteins binding to HSV-1 capsids. IFN induction prevented

HSV-1 infection of M $\phi$, and increased the cytosolic abundance of at least 12 proteins listed in the interferome database (Rusinova et al., 2013). Here, we assembled host protein-capsid complexes 
more distinct. These results are consistent with immunoelectron microscopy data showing that the surface of distinct V capsid types display different tegument epitopes (Radtke et al., 2010), and with cryoelectron tomography data revealing diminishing tegument densities from $\mathrm{V}_{0.1}, \mathrm{~V}_{0.5}, \mathrm{~V}_{1}$ capsids to C capsids (Anderson et al., 2014). Accordingly, capsids with different tegument composition recruit distinct sets of cytosolic proteins from brain tissue (Radtke et al., 2010), or macrophages as shown here. Host proteins may bind to viral proteins in both states, when they are soluble in the cytosol or the nucleoplasm, or when they are associated with capsids. From host proteins shown here to bind to ICPO (Everett et al., 1997) or EIF4H binding to vhs (pUL41; Page \& Read, 2010). Furthermore proteins involved in intracellular trafficking or virus assembly associated particularly with tegumented $\mathrm{V}$ capsids. For example, importin a5 (KPNA1) might mediate capsid targeting to the nuclear pores (Döhner et al., 2018; Döhner et al., 2021), while RAB1B contributes to the envelopment of cytosolic HSV-1 capsids (Zenner et al., 2011).

MxB binding to alphaherpesviral capsids. In addition to $M \times B$, the host-capsid complexes included other antiviral proteins which in turn might be counteracted by HSV-1 proteins. Several $M \phi_{\text {IFN }}$ proteins already know to restrict herpesviruses, e.g. STAT2, POLR1C, IFI16, DDX58 (RIG-I), and OAS2 (Kurt-Jones et al., 2017; Lum \& Cristea, 2021; Ma et al., 2018), bound preferentially to D capsids. As it was not known how MxB might restrict herpesviral infection (Crameri et al., 2018; Schilling et al., 2018; Vasudevan et al., 2018), we investigated its association with capsids further. B capsids are less sturdy and have not undergone the structural changes that stabilize the A and C capsids (Roos et al., proteins pUL17 and pUL25 (Sae-Ueng et al., 2014; Snijder et al., 2017), which are present on B, A, and C capsids (Anderson et al., 2014; Radtke et al., 2010; Snijder et al., 2017). As MxB bound to A, C

337 and $D$, but not to B capsids, it might recognize surface features formed during capsid stabilization, capsids. 


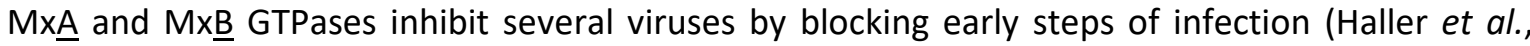
2015). MxB binding to HIV capsids depends on its N-terminal region (NTR) of about 90 residues and the GTPase domain (Betancor et al., 2019; Fricke et al., 2014; Smaga et al., 2019; Xie et al., 2021). Similarly, HSV-1 capsids bound $\mathrm{MxB}(1-715)$ and to a lesser extent $\mathrm{MxB}(26-715)$. But in contrast to HIV capsids (Betancor et al., 2019; Xie et al., 2021), HSV-1 capsids recruited also the GTPase deficient $\mathrm{MxB}(\mathrm{T} 151 \mathrm{~A})$ and the monomeric $\mathrm{MxB}(\mathrm{M} 574 \mathrm{D})$. These data indicate that the interaction of $\mathrm{MxB}$ with HSV-1 capsids depends on the NTE of 25 residues, its GTP/GDP status, but not on its dimerization. proteins as there was a considerable lag phase. $\mathrm{MxB}$ did not attack fully tegumented $\mathrm{V}_{0.1}$ capsids, while $V_{0.5}$ or $\mathrm{D}$ capsids were more susceptible. The large tegument protein pUL36 links other tegument proteins to the capsids; it is tightly associated with pUL17 and pUL25 at the CSVCs at the pentons, and it extends towards the 2-fold symmetry axes connecting neighbouring capsid faces (Coller et al., 2007; Huet et al. 2016; Liu et al., 2019; Newcomb \& Brown, 1991; Schipke et al., 2012). Our electron microscopy data suggest that MxB attacked the 5-fold symmetry axes as the punched capsids had dramatic dents on the capsid vertices. MxB might furthermore attack the portal cap, a cap of HSV1-pUL25 or its homologs in other herpesviruses, which seals the pUL6 portal after DNA packaging is completed (Liu et al., 2019; McElwee et al., 2018; Döhner et al. 2021; Naniima et al., al., 2010; Anderson et al., 2014); just not as fast, and not as efficient. Altogether, these results masking the MxB target structure, or by inhibiting its GTPase cycle. 
For the homologous MxA GTPase that limits infection of many RNA viruses (Haller et al., 2015), Gao

et al. (2011) proposed a restriction mechanism that involves GTP hydrolysis and a mechano-chemical coupling within ring-like oligomers with the GTPase domains being exposed on their outer diameter

(Gao et al., 2011). Similarly, MxB can also assemble into helical tubes with the NTE and the GTPase domain oriented outwards (Alvarez et al., 2017). Accordingly, MxB monomers and dimers might associate with the capsid vertices and insert between the hexons of neighbouring capsid faces. A to be ejected from the capsid into the nucleoplasm due to this intramolecular repulsion (BrandarizNunez et al., 2019; Döhner et al., 2021; Ojala et al., 2000; Rode et al., 2011). In uninfected cells, there is a low amount of constitutively expressed MxB localized at the NPCs (Crameri et al., 2018; Kane et al., 2018; Melen \& Julkunen, 1997), which might dislodge the portal cap and open the capsid portal on the incoming capsid to release the incoming genome into the nucleoplasm. capsid transport, genome uncoating at the NPCs, and/or the release of viral genomes into the 
al., 2014; Schulte et al., 2015; Xie et al., 2021). It will be interesting to determine whether MxB only competes for important HIV interactions with promoting host factors (reviewed in Temple et al., 2020), or whether it also induces HIV capsid disassembly.

Our data together with Schilling et al. (2018) and Crameri et al. (2018) suggest that the IFNinducible MxB restricts HSV-1, HSV-2, VZV, and possibly other herpesviruses, by promoting efficient capsid disassembly. We cannot exclude that a surplus of capsid- and NPC-associated MxB imposes further restrictions on intracellular transport and genome release into the nucleoplasm. However, if $\mathrm{MxB}(1-715)$ would disassemble viral capsids before they are oriented properly with their portal towards the NPCs, their genomes would end up in the cytosol and would not be delivered into the nucleoplasm. There are fewer incoming cytoplasmic capsids in cells expressing MxB (Crameri et al., 2018), and incoming VP5 is ubiquitinated and degraded by proteasomes in macrophages (Horan et al., 2013; Sun et al., 2019). Therefore, capsid disassembly intermediates might be degraded in cells, while we could characterize them in our biochemical cell-free assays in which proteases had been blocked.

The viral genomes exposed after MxB-induced capsid disassembly might be degraded by the DNase TREX1 (Sun et al., 2019), or stimulate the DNA sensors AIM2, cGAS, or IFI16, and the induction of antiviral host mechanisms. As an inoculation with destabilized HIV-1 capsids leads to an increased activation of the DNA sensor cGAS (Sumner et al., 2020), the IFN-induced increased MxB expression might lead to a similar outcome in cells infected with herpesviruses. Accordingly, MxB may not only restrict herpesviruses by capsid disassembly, but also increase the exposure of viral genomes to cytosolic DNA sensors, which in turn would induce an IFN response, inflammation as well as innate and adaptive immune responses. Thus, $\mathrm{MxB}$ could be the long sought-after capsid sensor that destroys the sturdy herpesvirus capsids, and possibly HIV cores and other viral capsids, to promote host viral genome sensing.

\section{MATERIALS AND METHODS}



per week. BHK-21 (ATCC CCL-10) and Vero cells (ATCC CCL-81) were cultured in MEM Eagle with 1\% NEAA (Cytogen, Wetzlar, Germany) and $10 \%$ or $7.5 \%$ (v/v) FBS, respectively (Good Forte; PAN-

The cells were cultured with $1000 \mathrm{U} / \mathrm{mL}$ human type I IFN- $\alpha 2 a$ (M $\phi_{\text {IFN }}$; R\&D Systems, Minneapolis, Minnesota, USA) or left untreated for $16 \mathrm{~h}$. cell lines stably expressing $M \times B(1-715), M \times B(1-715 / K 131 A), M \times B(1-715 / T 151 A), M \times B(1-715 / M 574 D)$,

$\mathrm{MxB}(26-715)$, or $\mathrm{MxA}(1-662)$ upon transduction with the respective $\mathrm{pLVX}$ vectors with an engineered

Kozak sequence to favor expression of the $\mathrm{MxB}(1-715)$ over the $\mathrm{MxB}(26-715)$ proteins (Schilling et al. of MxB (GenBAnk NM_002463), and A549-MxB(1-715)-MxB(26-715) cells expressing untagged $\mathrm{MxB}(1-715)$ and $\mathrm{MxB}(26-715)$ using the pLKOD-Ires-Puro vector (Clontech Takara Bio, Mountain View, United States). MeWo cells (kind gift from Graham Ogg; University of Oxford, Oxford, UK) were cultured in MEM with $10 \%$ FCS, NEAA, and $1 \mathrm{mM}$ sodium pyruvate. al., 1998; kind gift from Pat Spear, Northwestern Medical School, Chicago, USA), and HSV-2 strain prepared as reported before (Döhner et al., 2006; Grosche et al., 2019). Extracellular particles were 442 harvested from the supernatant of BHK-21 cells infected with 3 to $4 \times 10^{4} \mathrm{PFU} / \mathrm{mL}$ (MOI of $4430.01 \mathrm{PFU} /$ cell) for 2 to 3 days until the cells had detached from the culture flasks, and plaque-titrated 444 on Vero cells. VZV rOka (kind gift from Jeffrey Cohen, NIH, Bethesda, US) was maintained in infected 
MeWo cells (Cohen \& Seidel, 1993; Hertzog et al., 2020). After 2 to 4 days, the VZV infected cells as

indicated by cytopathic effects were harvested, mixed with naïve MeWo cells at a ratio of 1:4 to 1:8

447 for continued culture. Aliquots of frozen infected cells were used to inoculate cultures used for capsid preparation.

HSV-1 infection. THP-1 were seeded at $2.5 \times 10^{5}$ cells per 6-well, treated with $100 \mathrm{nM}$ PMA

(Sigma-Aldrich, Germany) for $48 \mathrm{~h}$ and used immediately $(\mathrm{M} \phi)$ or after 3 days of rest $\left(M \phi_{R}\right)$. The cells

cell culture grade fatty-acid free bovine serum albumin (BSA; PAA Laboratories $\mathrm{GmbH}$ ) for $30 \mathrm{~min}$,

and then shifted to regular culture medium at $37^{\circ} \mathrm{C}$ and $5 \% \mathrm{CO}_{2}$. At the indicated times, the cells and

the corresponding media were harvested separately and snap-frozen in liquid nitrogen. These

samples as well as and HSV-1 and HSV-2 inocula were titrated on Vero cells (Döhner et al., 2006;

Grosche et al., 2019).

Preparation of $\mathbf{V}_{0.1}, \mathbf{V}_{0.5}$ and $\mathbf{V}_{1}$ and $\mathbf{D}$ capsids. Extracellular HSV-1 or HSV-2 particles were

harvested by sedimentation at $12,000 \mathrm{rpm}$ for 90 minutes at $4^{\circ} \mathrm{C}$ (Type 19 rotor, Beckman-Coulter)

from the medium of BHK-21 cells ( $40 \times 175 \mathrm{~cm}^{2}$ flasks; $2-2.5 \times 10^{7}$ cells/flask) infected with 0.01

PFU/cell (2 to $6.7 \times 10^{4} \mathrm{PFU} / \mathrm{mL}$ ) for 2.5 days. The resulting medium pellets (MP) were resuspended in

$1 \mathrm{~h}$ which was then inactivated with $5 \mathrm{mg} / \mathrm{mL}$ trypsin inhibitor from soybean (SBTI; Fluka, buffer (2\% TX-100, 20 mM MES, 30 mM Tris, pH 7.4, 20 mM DTT, 1x protease inhibitor cocktail [PIs, of $20 \%(\mathrm{w} / \mathrm{v})$ sucrose cushions in $20 \mathrm{mM}$ MES, $30 \mathrm{mM}$ Tris, pH 7.4 with $10 \mathrm{mM}$ DTT, Pls with the 
472 tegument proteins were carefully removed. The pellets were resuspended in BRB80 (80 mM PIPES,

$473 \mathrm{pH} 6.8,12 \mathrm{mM} \mathrm{MgCl}$, $1 \mathrm{mM} \mathrm{EGTA}$ ) with $10 \mathrm{mM} \mathrm{DTT}$, Pls, $0.1 \mathrm{U} / \mathrm{mL}$ protease-free DNase I (Promega,

$474 \mathrm{USA}$ ), and $100 \mathrm{mg} / \mathrm{mL}$ protease-free RNase (Roth $\mathrm{GmbH}$, Germany) for $1 \mathrm{~h}$ at $37^{\circ} \mathrm{C}$ and then overnight at $4^{\circ} \mathrm{C}$. The capsids were sedimented at $110,000 \mathrm{~g}$ for $15 \mathrm{~min}$ at $4^{\circ} \mathrm{C}$ (TLA-120.2) and resuspended in capsid binding buffer (CBB: 5\% [w/v] sucrose, 20 mM HEPES-KOH, pH 7.3, $80 \mathrm{mM} \mathrm{K}$-acetate, $1 \mathrm{mM}$ EGTA, $2 \mathrm{mM} \mathrm{Mg}$-acetate, $10 \mathrm{mM}$ DTT and PIs) by ultrasound tip sonication at $40 \mathrm{~W}$ for about $5 \times 5$ seconds on ice. Furthermore, we treated $V_{0.1}$ capsids for 40 min at $37^{\circ} \mathrm{C}$ with $10 \mu \mathrm{g} / \mathrm{mL}$ trypsin in $\mathrm{CBB}$ lacking Pls to generate D capsids by limited digestion. After the addition of $5 \mathrm{mg} / \mathrm{mL} \mathrm{SBTI}$ for $10 \mathrm{~min}$ on ice to block the trypsin activity, the $D$ capsids were sedimented at $110,000 \times \mathrm{g}$ and $4^{\circ} \mathrm{C}$ for $15 \mathrm{~min}$ (TLA-120.2), and resuspended in CBB with PIs.

Preparation of nuclear A, B, and C capsids. HSV-1 nuclear capsids were prepared from $40 \times 175$ $\mathrm{cm}^{2}$ flasks with BHK-21 cells infected with $0.01 \mathrm{PFU} / \mathrm{cell}$ ( 3 to $4 \times 10^{4} \mathrm{PFU} / \mathrm{mL}$ ) for about 2.5 days (Anderson et al., 2014; Radtke et al., 2010; Radtke et al., 2014; Snijder et al., 2017; Wolfstein et al., 2006). VZV nuclear capsids were harvested from infected MeWo cells cultured in 5 to $10 \times 175 \mathrm{~cm}^{2}$ flasks at maximum syncytia formation but before cell lysis. The cells were harvested, resuspended in MKT buffer (20 mM MES, $30 \mathrm{mM}$ Tris, $\mathrm{pH}$ 7.4, $100 \mathrm{mM} \mathrm{KCl),} \mathrm{snap-frozen,} \mathrm{and} \mathrm{stored} \mathrm{at}-80^{\circ} \mathrm{C}$. Nuclear

A, B, and C capsids were separated by sedimentation at $50,000 \times \mathrm{g}$ and $4^{\circ} \mathrm{C}$ for 80 min (SW40Ti, Beckman Coulter) on linear 20 to 50\% sucrose gradients in TKE buffer (20 mM Tris, pH 7.5, $500 \mathrm{mM}$ resuspended in CBB with PIs.

Calibration of capsid concentration. To calibrate the amount of capsid equivalents (CAP eq) among different experiments, we compared all capsid preparations used in this study with a 
PIs [Roche cOmplete]), and adsorbed to nitrocellulose membranes (BioTrace ${ }^{\mathrm{TM}}$, Pall Laboratory) using

500 a 48-slot suction device (Bio-DOT-SF, Bio-Rad, Hercules, California, USA). The membranes were probed with a polyclonal rabbit serum raised against purified HSV-1 nuclear capsids (SY4563; Table S4; Döhner et al., 2018) followed by secondary antibodies conjugated to fluorescent infrared dyes (donkey-anti-rabbit IgG-IRDye1 800CW; Table S3), and documented with an Infrared Imaging System (Odyssey, Image Studio Lite Quantification Software, LI-COR Biosciences, Lincoln, Nebraska, USA). MPs harvested from one $175 \mathrm{~cm}^{2}$ flasks of BHK-21 cells infected with HSV-1 contained about 0.5 to 1 $\times 10^{9} \mathrm{PFU} / \mathrm{mL}$, and 0.75 to $1.5 \times 10^{9} \mathrm{CAP}_{\text {eq }} / \mathrm{mL}$. A nuclear HSV-1 capsid fraction prepared from one $175 \mathrm{~cm}^{2}$ flask contained about 0.5 to $1 \times 10^{7} \mathrm{CAP}_{\text {eq }}$ of A capsids, 1 to $2 \times 10^{7} \mathrm{CAP}_{\text {eq }}$ of B capsids, and 0.5 to $0.75 \times 10^{7} \mathrm{CAP}_{\text {eq }}$ of C capsids, and a nuclear VZV fraction from one $175 \mathrm{~cm}^{2}$ flasks of MeWo cells 2 to $4 \times 10^{5} \mathrm{CAP}_{\text {eq }}$ of $\mathrm{A}$ capsids, 0.5 to $1 \times 10^{6} \mathrm{CAP}_{\text {eq }}$ of $\mathrm{B}$ capsids, and 0.8 to $1.6 \times 10^{7} \mathrm{CAP}_{\text {eq }}$ of $\mathrm{C}$ 510 capsids. Capsid-host protein complexes were assembled in-solution using $7.5 \times 10^{8} \mathrm{CAP}_{\text {eq }} /$ condition

511 for MS and immunoblot experiments, and for the on-grid electron microscopy assay $2 \times 10^{7}$ $512 \quad \mathrm{CAP}_{\mathrm{eq}} /$ condition were used.

Preparation of cytosol. Cytosolic extracts were prepared as described before (Radtke et al., 2010; Radtke et al., 2014), dialyzed (7K MW cut-off cassettes; Slide-A-LyzerM, Thermo Scientific), snapfrozen and stored at $-80^{\circ} \mathrm{C}$. Prior to their use, the cytosols were supplemented with $1 \mathrm{mM} \mathrm{ATP,} 1 \mathrm{mM}$ GTP, $7 \mathrm{mM}$ creatine phosphate, $5 \mathrm{mM}$ DTT, and PIs (Roche cOmplete), and centrifuged at 130,000 g

517 for $30 \mathrm{~min}$ at $4^{\circ} \mathrm{C}$ (TLA-120.2). We added nocodazole to $25 \mu \mathrm{M}$ to the cytosols, and left them either untreated (ATP/GTP high) or supplemented them with $10 \mathrm{U} / \mathrm{mL}$ apyrase (Sigma; ATP/GTP ${ }^{\text {low }}$ ) for $15 \mathrm{~min}$ at RT.

Assembly of capsid-host protein complexes in-solution. Capsids were resuspended in CBB and cytosol at a protein concentration of $0.2 \mathrm{mg} / \mathrm{mL}$ in an assay volume of $60 \mu \mathrm{L}$ per sample on a rotating 522 platform at $800 \mathrm{rpm}$ for $1 \mathrm{~h}$ at $37^{\circ} \mathrm{C}$ (c.f. Fig. S1). The capsid-host protein complexes were sedimented 523 through a $30 \%$ sucrose cushion at $110,000 \mathrm{~g}$ for $20 \mathrm{~min}$ at $4^{\circ} \mathrm{C}$ (TLA-100, Beckman-Coulter), 524 resuspended in CBB by ultrasound tip sonication at $40 \mathrm{~W}$ for about $5 \times 5$ seconds on ice, and analysed by mass spectrometry, immunoblot, or electron microscopy (Radtke et al., 2014). 
SDS-PAGE and immunoblot. The samples were lysed in Laemmli buffer (1\% [w/v] SDS, $50 \mathrm{mM}$

527 Tris- $\mathrm{HCl}, \mathrm{pH} 6.8,1 \%[\mathrm{v} / \mathrm{v}] \beta$-mercaptoethanol, $5 \%[\mathrm{v} / \mathrm{v}]$ glycerol, bromophenol blue, Pls [Roche

cOmplete]). The proteins were separated on linear 7.5 to $12 \%$ or 10 to $15 \%$ SDS-PAGE, transferred to

methanol-activated PVDF membranes, probed with rabbit or murine primary antibodies (Table S3)

and secondary antibodies conjugated to fluorescent infrared dyes (anti-rabbit IgG-IRDye1 800CW; centrifuge, resuspended in $2 \mathrm{M}$ Tris- $\mathrm{HCl}$ buffer before reduction and alkylation using $10 \mathrm{mM}$ Tris(2operated in Data-Dependent Analysis mode (DDA, XCalibur software v.3.0, Thermo Fisher). 
553 (https://maxquant.net/maxquant/, v1.6.2.10; https://maxquant.net/perseus/, v1.6.5.0; Cox \& Mann, 2008;

554 Tyanova et al., 2016a; Tyanova et al., 2016b). The iBAQ intensities were normalized across all 555 samples to the overall median intensity of the HSV-1 capsid protein VP5. Cytosol and beads incubated with cytosol samples were normalized to all proteins detected in at least three replicates in each condition. Significant differences between given conditions were determined by a two-sided Welch t-test on protein groups present in three replicates of at least one condition, followed by permutation-based FDR statistics (250 permutations), using an absolute $\log _{2}$ difference cut-off of 1.5 and an FDR cut-off of 0.01 . To characterize the IFN induction, we annotated proteins reported as being induced by IFN type-I as ISGs proteins (InterferomeDB, > $2 \mathrm{x}$ change;

test against ISGs proteins as well as all Gene Ontology (GO) terms for enrichment analysis of proteins upregulated in IFN-induced $M \phi_{\text {IFN }}$ cytosol over $M \phi_{R}$ cytosol ( $\log _{2}$ difference $\geq 1.5$; unadjusted p-value $<0.05$ ). The data were summarized in volcano or bar plots (GraphPad Prism v5.0, https://www.graphpad.com/; Perseus v1.6.5.0; Tyanova et al., 2016b).

Interaction Network Assembly. We focused our analysis on proteins that showed specific differences from one capsid preparation to the other, within the same cytosol preparation, and considered host proteins with an enrichment higher than $1.5 \log _{2}$ fold changes and a permutationbased FDR $<0.05$ as specifically enriched. To visualize enrichment among different capsid-host protein complexes, we generated integrative networks using Cytoscape (http://www.cytoscape.org/; v3.7.2) and STRING (confidence score: 0.7; Szklarczyk et al., 2019). STRING uses a combination of databases on co-expression, conserved occurrences, GO terms and Kyoto Encyclopedia of Genes and

574 Genomes (KEGG; https://www.genome.jp/kegg/; Kanehisa \& Goto, 2000; Kanehisa, 2019; Kanehisa et 575 al., 2021). To assemble pathway enrichments, we used DAVID, a Database for Annotation, 576 Visualization and Integrated Discovery (https://david.ncifcrf.gov/home.jsp; v6.8; Huang da et al., 2009a; 577 Huang da et al., 2009b) and the Cytoscape plug-ins ClueGO and CluePedia 578 (http://apps.cytoscape.org/apps/cluego, v2.5.7; http://apps.cytoscape.org/apps/cluepedia, v1.5.7; Bindea et al., 2009; Bindea et al., 2013). 
Electron microscopy. Capsid-host protein complexes were assembled at ATP/GTP ${ }^{\text {high }}$ in solution,

581

582

583

584

585

586

587

588

589

590

591

592

593

594

595

596

597

598

599

600

601

602

603

604

605

harvested by ultracentrifugation, resuspended in $\mathrm{CBB}$, and adsorbed onto enhanced hydrophilicity400 mesh formvar- and carbon-coated copper grids (Stork Veco, The Netherlands; Radtke et al., 2010; Roos et al., 2009). Moreover, capsids at a concentration of $1 \times 10^{7} \mathrm{CAP}_{\text {eq }} / \mathrm{mL}$ were adsorbed directly for 20 min at RT onto the grids. The grids were incubated on a $10 \mu \mathrm{L}$ drop of cytosol with a protein concentration of $0.2 \mathrm{mg} / \mathrm{mL}$ and ATP/GTP ${ }^{\text {high }}$ in a humid chamber for $1 \mathrm{~h}$ at $37^{\circ} \mathrm{C}$. The samples were left untreated or labelled with anti-VP5 (pAb NC-1) and protein-A gold (10 nm diameter; Cell Microscopy Centre, Utrecht School of Medicine, The Netherlands). For both protocols, the grids were washed with PBS and $\mathrm{ddH}_{2} \mathrm{O}$, contrasted with $2 \%$ uranyl acetate at $\mathrm{pH} 4.4$, air dried, and analysed by transmission electron microscopy (Morgani or Tecnai; FEI, Einthoven, The Netherlands). The capsid morphology was evaluated for about 100 structures/assay from about 15 randomly selected images of $2.7 \mu \mathrm{m}^{2}$ of three biological replicates. We classified capsomer-containing structures as punched, if they lacked one or more of their vertices but still had an icosahedral shape, and as flat shells, if they lacked the icosahedral shape but contained capsomers, and scored them as one capsid equivalent structure if they contained more than 100 capsomers.

Capsid DNA uncoating assay. D capsids were incubated with cytosols from A549-control, A549-MxB(1-715), A549-MxB(M574D), or A549-MxB-FLAG for $1 \mathrm{~h}$ at $37^{\circ} \mathrm{C}$ or treated for 5 min with $1 \%$ SDS followed by 10 min with $10 \%$ TX-100(Ojala et al., 2000). The viral genomes released during the assay were degraded by adding $50 \mathrm{U} / \mathrm{mL}$ of benzonase for $1 \mathrm{~h}$ at $37^{\circ} \mathrm{C}$, and the remaining protected DNA was purified with the DNA Blood Mini Kit (Qiagen, Hilden, Germany) and quantified by real-time PCR on a qTower ${ }^{3}$ (Analytik Jena, Jena, Germany). The SYBR Green assay was performed with the Luna Universal qPCR Master Mix (NEB, Ipswich, MA, USA) according to the manufacturer's instructions with primers specific for HSV-1 gB (UL27 gene) (HSV1_2 SYBR fwd: 5'gtagccgtaaaacggggaca-3' and HSV1_2 SYBR rev: 5'-ccgacctcaagtacaacccc-3'; Engelmann et al., 2008). Standards and samples were run in triplicates and results expressed as \% released viral DNA with the SDS/Tx-100 treatment normalized to $100 \%$. 
607 Friedman and one-way analyses of variance with a Dunns or Bonferroni post-testing (GraphPad Prism

608 v5.0; https://www.graphpad.com/).

Data availability: The datasets produced in this study are available at PRIDE (PXD028276;

\section{ACKNOWLEDGMENT}

We thank Katinka Döhner and Franziska Hüsers (Institute of Virology, Hannover Medical School) for their generous donation of virus strains and invaluable antibodies. Immunology Unit to JR), the NIH (NIGMS, GM114141 to IMC), an EU ERC consolidator grant (ERC-CoG 
631 and curated the respective data. MCS, VG, APir, APic, and BS analysed the data. MCS, AHM, JH, AB,

632 APo, UP, and SW produced the resources used in this study. FA, SW, TG, RB, IC, JR, and GK

633 contributed to the analysis of the data and the discussion of the content. All authors reviewed and

634 edited the manuscript before submission.

\section{COMPETING INTEREST}

636 The authors have declared that no competing interests exist. 


\section{REFERENCES}

Alvarez FJD, He S, Perilla JR, Jang S, Schulten K, Engelman AN, Scheres SHW, \& Zhang P (2017) CryoEM structure of $\mathrm{MxB}$ reveals a novel oligomerization interface critical for HIV restriction. Sci Adv 3: e1701264

Anderson F, Savulescu AF, Rudolph K, Schipke J, Cohen I, Ibiricu I, Rotem A, Grunewald K, Sodeik B, \& Harel A (2014) Targeting of viral capsids to nuclear pores in a cell-free reconstitution system. Traffic 15: 1266-1281

Arvin AM \& Abendroth A (2021) Varicella-Zoster Virus. In Fields Virology: DNA Viruses, Howley PM, Knipe DM, Cohen JL, Damania BA (eds) pp 445-488. Wolters Kluwer Health/Lippincott Williams \& Wilkins; 7th edition (May 17, 2021): Berlin, Heidelberg

Ashburner M, Ball CA, Blake JA, Botstein D, Butler H, Cherry JM, Davis AP, Dolinski K, Dwight SS, Eppig JT, Harris MA, Hill DP, Issel-Tarver L, Kasarskis A, Lewis S, Matese JC, Richardson JE, Ringwald M, Rubin GM, \& Sherlock G (2000) Gene ontology: tool for the unification of biology. The Gene Ontology Consortium. Nat Genet 25: 25-29

Bauer DW, Huffman JB, Homa FL, \& Evilevitch A (2013) Herpes virus genome, the pressure is on. J Am Chem Soc 135: 11216-11221

Betancor G, Dicks MDJ, Jimenez-Guardeño JM, Ali NH, Apolonia L, \& Malim MH (2019) The GTPase Domain of MX2 Interacts with the HIV-1 Capsid, Enabling Its Short Isoform to Moderate Antiviral Restriction. Cell Rep 29: 1923-1933.e3

Bindea G, Galon J, \& Mlecnik B (2013) CluePedia Cytoscape plugin: pathway insights using integrated experimental and in silico data. Bioinformatics 29: 661-663

Bindea G, Mlecnik B, Hackl H, Charoentong P, Tosolini M, Kirilovsky A, Fridman WH, Pages F, Trajanoski Z, \& Galon J (2009) ClueGO: a Cytoscape plug-in to decipher functionally grouped gene ontology and pathway annotation networks. Bioinformatics 25: 1091-1093

Brandariz-Nunez A, Liu T, Du T, \& Evilevitch A (2019) Pressure-driven release of viral genome into a host nucleus is a mechanism leading to herpes infection. Elife 8: 10.7554/eLife.47212

Buffone C, Schulte B, Opp S, \& Diaz-Griffero F (2015) Contribution of MxB oligomerization to HIV-1 capsid binding and restriction. J Virol 89: 3285-3294

Cabrera JR, Manivanh R, North BJ, \& Leib DA (2019) The ESCRT-Related ATPase Vps4 Is Modulated by Interferon during Herpes Simplex Virus 1 Infection. mBio 10: 10.1128/mBio.02567-18

Cao H, Krueger EW, Chen J, Drizyte-Miller K, Schulz ME, \& McNiven MA (2020) The anti-viral dynamin family member MxB participates in mitochondrial integrity. Nat Commun 11: 1048-w

Carter-Timofte ME, Paludan SR, \& Mogensen TH (2018) RNA Polymerase III as a Gatekeeper to Prevent Severe VZV Infections. Trends Mol Med 24: 904-915

Chen Y, Zhang L, Graf L, Yu B, Liu Y, Kochs G, Zhao Y, \& Gao S (2017) Conformational dynamics of dynamin-like MXA revealed by single-molecule FRET. Nat Commun 8: 15744

Cohen GH, Ponce de Leon M, Diggelmann H, Lawrence WC, Vernon SK, \& Eisenberg RJ (1980) Structural analysis of the capsid polypeptides of herpes simplex virus types 1 and 2. J Virol 34: 521-531

Cohen JI \& Seidel KE (1993) Generation of varicella-zoster virus (VZV) and viral mutants from cosmid DNAs: VZV thymidylate synthetase is not essential for replication in vitro. Proc Natl Acad Sci U SA 90: 7376-7380

Coller KE, Lee JI, Ueda A, \& Smith GA (2007) The capsid and tegument of the alphaherpesviruses are linked by an interaction between the UL25 and VP1/2 proteins. J Virol 81: 11790-11797

Cox J \& Mann M (2008) MaxQuant enables high peptide identification rates, individualized p.p.b.range mass accuracies and proteome-wide protein quantification. Nat Biotechnol 26: 1367-1372 
Crameri M, Bauer M, Caduff N, Walker R, Steiner F, Franzoso FD, Gujer C, Boucke K, Kucera T, Zbinden A, Munz C, Fraefel C, Greber UF, \& Pavlovic J (2018) MxB is an interferon-induced restriction factor of human herpesviruses. Nat Commun 9: 1980-2

Crump CM (2018) Virus Assembly and Egress of HSV. Adv Exp Med Biol 1045: 23-44

Crump CM, Yates C, \& Minson T (2007) Herpes simplex virus type 1 cytoplasmic envelopment requires functional Vps4. J Virol 81: 7380-7387

Dai X \& Zhou ZH (2018) Structure of the herpes simplex virus 1 capsid with associated tegument protein complexes. Science 360: 10.1126/science.aao7298. Epub 2018 Apr 5

Diefenbach RJ (2015) Conserved tegument protein complexes: Essential components in the assembly of herpesviruses. Virus Res 210: 308-317

Döhner K, Cornelius A, Serrero MC, \& Sodeik B (2021) Herpesvirus Capsids on Their Journey to the Center of the Cell. Current Opinion of Virology 50: 147-158

Döhner K, Ramos-Nascimento A, Bialy D, Anderson F, Hickford-Martinez A, Rother F, Koithan T, Rudolph K, Buch A, Prank U, Binz A, Hugel S, Lebbink RJ, Hoeben RC, Hartmann E, Bader M, Bauerfeind R, \& Sodeik B (2018) Importin alpha1 is required for nuclear import of herpes simplex virus proteins and capsid assembly in fibroblasts and neurons. PLoS Pathog 14: e1006823

Döhner K, Radtke K, Schmidt S, \& Sodeik B (2006) Eclipse phase of herpes simplex virus type 1 infection: Efficient dynein-mediated capsid transport without the small capsid protein VP26. J Virol 80: 8211-8224

Engelmann I, Petzold DR, Kosinska A, Hepkema BG, Schulz TF, \& Heim A (2008) Rapid quantitative PCR assays for the simultaneous detection of herpes simplex virus, varicella zoster virus, cytomegalovirus, Epstein-Barr virus, and human herpesvirus 6 DNA in blood and other clinical specimens. J Med Virol 80: 467-477

Everett RD, Meredith M, Orr A, Cross A, Kathoria M, \& Parkinson J (1997) A novel ubiquitin-specific protease is dynamically associated with the PML nuclear domain and binds to a herpesvirus regulatory protein. EMBO J 16: 1519-1530

Flohr F, Schneider-Schaulies S, Haller O, \& Kochs G (1999) The central interactive region of human MxA GTPase is involved in GTPase activation and interaction with viral target structures. FEBS Lett 463: $24-28$

Fribourgh JL, Nguyen HC, Matreyek KA, Alvarez FJD, Summers BJ, Dewdney TG, Aiken C, Zhang P, Engelman A, \& Xiong Y (2014) Structural insight into HIV-1 restriction by MxB. Cell Host Microbe 16: $627-638$

Fricke T, White TE, Schulte B, de Souza Aranha Vieira, D. A., Dharan A, Campbell EM, Brandariz-Nunez $A$, \& Diaz-Griffero $F(2014)$ MxB binds to the HIV-1 core and prevents the uncoating process of HIV-1. Retrovirology 11: 68-x

Gao S, von der Malsburg A, Dick A, Faelber K, Schroder GF, Haller O, Kochs G, \& Daumke O (2011) Structure of myxovirus resistance protein a reveals intra- and intermolecular domain interactions required for the antiviral function. Immunity 35: 514-525

Gene Ontology Consortium (2021) The Gene Ontology resource: enriching a GOld mine. Nucleic Acids Res 49: D325-D334

Gershon AA, Breuer J, Cohen JI, Cohrs RJ, Gershon MD, Gilden D, Grose C, Hambleton S, Kennedy PG, Oxman MN, Seward JF, \& Yamanishi K (2015) Varicella zoster virus infection. Nat Rev Dis Primers 1: 15016

Goujon C, Moncorge O, Bauby H, Doyle T, Barclay WS, \& Malim MH (2014) Transfer of the aminoterminal nuclear envelope targeting domain of human MX2 converts MX1 into an HIV-1 resistance factor. J Virol 88: 9017-9026

Goujon C, Moncorge O, Bauby H, Doyle T, Ward CC, Schaller T, Hue S, Barclay WS, Schulz R, \& Malim $\mathrm{MH}$ (2013) Human MX2 is an interferon-induced post-entry inhibitor of HIV-1 infection. Nature 502: 559-562 
Grosche L, Döhner K, Düthorn A, Hickford-Martinez A, Steinkasserer A, \& Sodeik B (2019) Herpes Simplex Virus Type 1 Propagation, Titration and Single-step Growth Curves. Bio-protocol: e3441

Haller O, Staeheli P, Schwemmle M, \& Kochs G (2015) Mx GTPases: dynamin-like antiviral machines of innate immunity. Trends Microbiol 23: 154-163

Hammond C \& Helenius A (1994) Quality control in the secretory pathway: retention of a misfolded viral membrane glycoprotein involves cycling between the ER, intermediate compartment, and Golgi apparatus. J Cell Biol 126: 41-52

Hertzog J, Rigby RE, Roll S, Cursi C, Chauveau L, Davenne T, \& Rehwinkel J (2021) Varicella-Zoster Virus ORF9 Is an Antagonist of the DNA Sensor cGAS. bioRxiv: 2020.02.11.943415V2

Hertzog J \& Rehwinkel J (2020) Regulation and inhibition of the DNA sensor cGAS. EMBO Rep 21: e51345

Horan KA, Hansen K, Jakobsen MR, Holm CK, Soby S, Unterholzner L, Thompson M, West JA, Iversen $M B$, Rasmussen SB, Ellermann-Eriksen S, Kurt-Jones E, Landolfo S, Damania B, Melchjorsen J, Bowie AG, Fitzgerald KA, \& Paludan SR (2013) Proteasomal degradation of herpes simplex virus capsids in macrophages releases DNA to the cytosol for recognition by DNA sensors. J Immunol 190: $2311-2319$

Huang da W, Sherman BT, \& Lempicki RA (2009a) Bioinformatics enrichment tools: paths toward the comprehensive functional analysis of large gene lists. Nucleic Acids Res 37: 1-13

Huang da W, Sherman BT, \& Lempicki RA (2009b) Systematic and integrative analysis of large gene lists using DAVID bioinformatics resources. Nat Protoc 4: 44-57

Hubel P, Urban C, Bergant V, Schneider WM, Knauer B, Stukalov A, Scaturro P, Mann A, Brunotte L, Hoffmann HH, Schoggins JW, Schwemmle M, Mann M, Rice CM, \& Pichlmair A (2019) A proteininteraction network of interferon-stimulated genes extends the innate immune system landscape. Nat Immunol 20: 493-502

Huet A, Makhov AM, Huffman J, Vos M, Homa FL, \& Conway JF (2016) Extensive subunit contacts underpin herpesvirus capsid stability and interior-to-exterior allostery. Nat Struc \& Mol Biol 23: 531-540

Huffmaster NJ, Sollars PJ, Richards AL, Pickard GE, \& Smith GA (2015) Dynamic ubiquitination drives herpesvirus neuroinvasion. Proc Natl Acad Sci U S A 112: 12818-12823

Justice JL, Kennedy MA, Hutton JE, Liu D, Song B, Phelan B, \& Cristea IM (2021) Systematic profiling of protein complex dynamics reveals DNA-PK phosphorylation of IFI16 en route to herpesvirus immunity. Sci Adv 7: 10.1126/sciadv.abg6680. Print 2021 Jun

Kane M, Yadav SS, Bitzegeio J, Kutluay SB, Zang T, Wilson SJ, Schoggins JW, Rice CM, Yamashita M, Hatziioannou T, \& Bieniasz PD (2013) MX2 is an interferon-induced inhibitor of HIV-1 infection. Nature 502: 563-566

Kane M, Rebensburg SV, Takata MA, Zang TM, Yamashita M, Kvaratskhelia M, \& Bieniasz PD (2018) Nuclear pore heterogeneity influences HIV-1 infection and the antiviral activity of MX2. Elife 7: 10.7554/eLife.35738

Kanehisa M (2019) Toward understanding the origin and evolution of cellular organisms. Protein Sci 28: 1947-1951

Kanehisa M, Furumichi M, Sato Y, Ishiguro-Watanabe M, \& Tanabe M (2021) KEGG: integrating viruses and cellular organisms. Nucleic Acids Res 49: D545-D551

Kanehisa M \& Goto S (2000) KEGG: kyoto encyclopedia of genes and genomes. Nucleic Acids Res 28: 27-30

King MC, Raposo G, \& Lemmon MA (2004) Inhibition of nuclear import and cell-cycle progression by mutated forms of the dynamin-like GTPase MxB. Proc Natl Acad Sci U S A 101: 8957-8962

Knipe DM, Heldwein EE, Mohr IJ, Sodroski CN (2021) Herpes Simplex Viruses: Mechanisms of Lytic and Latent Infection. In Fields Virology: DNA Viruses, Howley PM, Knipe DM, Cohen JL, Damania 
BA (eds) pp 235-296. Wolters Kluwer Health/Lippincott Williams \& Wilkins; 7th edition (May 17, 2021)

Kurt-Jones EA, Orzalli MH, \& Knipe DM (2017) Innate Immune Mechanisms and Herpes Simplex Virus Infection and Disease. Adv Anat Embryol Cell Biol 223: 49-75

Liu SY, Sanchez DJ, Aliyari R, Lu S, \& Cheng G (2012) Systematic identification of type I and type II interferon-induced antiviral factors. Proc Natl Acad Sci U S A 109: 4239-4244

Liu YT, Jih J, Dai X, Bi GQ, \& Zhou ZH (2019) Cryo-EM structures of herpes simplex virus type 1 portal vertex and packaged genome. Nature 570: 257-261

Liu Z, Pan Q, Ding S, Qian J, Xu F, Zhou J, Cen S, Guo F, \& Liang C (2013) The interferon-inducible MxB protein inhibits HIV-1 infection. Cell Host Microbe 14: 398-410

Lum KK \& Cristea IM (2021) Host Innate Immune Response and Viral Immune Evasion During Alphaherpesvirus Infection. Curr Issues Mol Biol 42: 635-686

Ma Z, Ni G, \& Damania B (2018) Innate Sensing of DNA Virus Genomes. Annu Rev Virol 5: 341-362

McElwee M, Vijayakrishnan S, Rixon F, \& Bhella D (2018) Structure of the herpes simplex virus portalvertex. PLoS Biol 16: e2006191

Melen K \& Julkunen I (1997) Nuclear cotransport mechanism of cytoplasmic human MxB protein. J Biol Chem 272: 32353-32359

Melen K, Keskinen P, Ronni T, Sareneva T, Lounatmaa K, \& Julkunen I (1996) Human MxB protein, an interferon-alpha-inducible GTPase, contains a nuclear targeting signal and is localized in the heterochromatin region beneath the nuclear envelope. J Biol Chem 271: 23478-23486

Naniima P, Naimo E, Koch S, Curth U, Alkharsah KR, Stroh U, Binz A, Beneke JM, Vollmer B, Boning H, Borst EM, Desai $P$, Bohne J, Messerle M, Bauerfeind R, Legrand $P$, Sodeik B, Schulz TF, \& Krey T (2021) Assembly of infectious Kaposi's sarcoma-associated herpesvirus progeny requires formation of a pORF19 pentamer. PLoS Biol 19: e3001423

Newcomb WW \& Brown JC (1991) Structure of the herpes simplex virus capsid: effects of extraction with guanidine hydrochloride and partial reconstitution of extracted capsids. J Virol 65: 613-620

Ojala PM, Sodeik B, Ebersold MW, Kutay U, \& Helenius A (2000) Herpes simplex virus type 1 entry into host cells: reconstitution of capsid binding and uncoating at the nuclear pore complex in vitro. Mol Cell Biol 20: 4922-4931

Page HG \& Read GS (2010) The virion host shutoff endonuclease (UL41) of herpes simplex virus interacts with the cellular cap-binding complex elF4F. J Virol 84: 6886-6890

Paludan SR, Reinert LS, \& Hornung V (2019) DNA-stimulated cell death: implications for host defence, inflammatory diseases and cancer. Nat Rev Immunol 19: 141-153

Pilla C, Emanuelli T, Frassetto SS, Battastini AM, Dias RD, \& Sarkis JJ (1996) ATP diphosphohydrolase activity (apyrase, EC 3.6.1.5) in human blood platelets. Platelets 7: 225-230

Radtke K, Anderson F, \& Sodeik B (2014) A precipitation-based assay to analyze interactions of viral particles with cytosolic host factors. Methods Mol Biol 1144: 191-208

Radtke K, Kieneke D, Wolfstein A, Michael K, Steffen W, Scholz T, Karger A, \& Sodeik B (2010) Plusand minus-end directed microtubule motors bind simultaneously to herpes simplex virus capsids using different inner tegument structures. PLoS Pathog 6: e1000991

Rode K, Döhner K, Binz A, Glass M, Strive T, Bauerfeind R, \& Sodeik B (2011) Uncoupling uncoating of herpes simplex virus genomes from their nuclear import and gene expression. $J$ Virol 85: 42714283

Rodriguez MC, Dybas JM, Hughes J, Weitzman MD, \& Boutell C (2020) The HSV-1 ubiquitin ligase ICPO: Modifying the cellular proteome to promote infection. Virus Res 285: 198015

Roos WH, Radtke K, Kniesmeijer E, Geertsema H, Sodeik B, \& Wuite GJ (2009) Scaffold expulsion and genome packaging trigger stabilization of herpes simplex virus capsids. Proc Natl Acad Sci U S A 106: $9673-9678$ 
Rusinova I, Forster S, Yu S, Kannan A, Masse M, Cumming H, Chapman R, \& Hertzog PJ (2013) Interferome v2.0: an updated database of annotated interferon-regulated genes. Nucleic Acids Res 41: 1040

Sae-Ueng U, Liu T, Catalano CE, Huffman JB, Homa FL, \& Evilevitch A (2014) Major capsid reinforcement by a minor protein in herpesviruses and phage. Nucleic Acids Res 42: 9096-9107

Sandbaumhüter M, Döhner K, Schipke J, Binz A, Pohlmann A, Sodeik B, \& Bauerfeind R (2013) Cytosolic herpes simplex virus capsids not only require binding inner tegument protein pUL36 but also pUL37 for active transport prior to secondary envelopment. Cell Microbiol 15: 248-269

Schilling M, Bulli L, Weigang S, Graf L, Naumann S, Patzina C, Wagner V, Bauersfeld L, Goujon C, Hengel H, Halenius A, Ruzsics Z, Schaller T, \& Kochs G (2018) Human MxB Protein Is a Panherpesvirus Restriction Factor. J Virol 92: 10.1128/JVI.01056-18. Print 2018 Sep 1

Schipke J, Pohlmann A, Diestel R, Binz A, Rudolph K, Nagel CH, Bauerfeind R, \& Sodeik B (2012) The C terminus of the large tegument protein pUL36 contains multiple capsid binding sites that function differently during assembly and cell entry of herpes simplex virus. J Virol 86: 3682-3700

Schneider SM, Lee BH, \& Nicola AV (2021) Viral entry and the ubiquitin-proteasome system. Cell Microbiol 23: e13276

Schulte B, Buffone C, Opp S, Di Nunzio F, De Souza Aranha Vieira, D. A., Brandariz-Nunez A, \& DiazGriffero F (2015) Restriction of HIV-1 Requires the N-Terminal Region of MxB as a Capsid-Binding Motif but Not as a Nuclear Localization Signal. J Virol 89: 8599-8610

Shannon P, Markiel A, Ozier O, Baliga NS, Wang JT, Ramage D, Amin N, Schwikowski B, \& Ideker T (2003) Cytoscape: a software environment for integrated models of biomolecular interaction networks. Genome Res 13: 2498-2504

Smaga SS, Xu C, Summers BJ, Digianantonio KM, Perilla JR, \& Xiong Y (2019) MxB Restricts HIV-1 by Targeting the Tri-hexamer Interface of the Viral Capsid. Structure 27: 1234-1245.e5

Snijder J, Radtke K, Anderson F, Scholtes L, Corradini E, Baines J, Heck AJR, Wuite GJL, Sodeik B, \& Roos WH (2017) Vertex-Specific Proteins pUL17 and pUL25 Mechanically Reinforce Herpes Simplex Virus Capsids. J Virol 91: 10.1128/JVI.00123-17. Print 2017 Jun 15

Stempel M, Chan B, \& Brinkmann MM (2019) Coevolution pays off: Herpesviruses have the license to escape the DNA sensing pathway. Med Microbiol Immunol 208: 495-512

Sumner RP, Harrison L, Touizer E, Peacock TP, Spencer M, Zuliani-Alvarez L, \& Towers GJ (2020) Disrupting HIV-1 capsid formation causes cGAS sensing of viral DNA. EMBO J 39: e103958

Sun C, Luecke S, Bodda C, Jonsson KL, Cai Y, Zhang BC, Jensen SB, Nordentoft I, Jensen JM, Jakobsen MR, \& Paludan SR (2019) Cellular Requirements for Sensing and Elimination of Incoming HSV-1 DNA and Capsids. J Interferon Cytokine Res 39: 191-204

Szklarczyk D, Gable AL, Lyon D, Junge A, Wyder S, Huerta-Cepas J, Simonovic M, Doncheva NT, Morris JH, Bork P, Jensen L, \& Mering CV (2019) STRING v11: protein-protein association networks with increased coverage, supporting functional discovery in genome-wide experimental datasets. Nucleic Acids Res 47: D607-D613

Temple J, Tripler TN, Shen Q, \& Xiong Y (2020) A snapshot of HIV-1 capsid-host interactions. Curr Res Struct Biol 2: 222-228

Tsuchiya S, Yamabe M, Yamaguchi Y, Kobayashi Y, Konno T, \& Tada K (1980) Establishment and characterization of a human acute monocytic leukemia cell line (THP-1). Int J Cancer 26: 171-176

Turan A, Grosche L, Krawczyk A, Muhl-Zurbes $P$, Drassner C, Duthorn A, Kummer M, Hasenberg $M$, Voortmann S, Jastrow H, Dorrie J, Schaft N, Kraner M, Döhner K, Sodeik B, Steinkasserer A, \& Heilingloh CS (2019) Autophagic degradation of lamins facilitates the nuclear egress of herpes simplex virus type 1. J Cell Biol 218: 508-523

Tyanova S, Temu T, \& Cox J (2016) The MaxQuant computational platform for mass spectrometrybased shotgun proteomics. Nat Protoc 11: 2301-2319 
Tyanova S, Temu T, Sinitcyn P, Carlson A, Hein MY, Geiger T, Mann M, \& Cox J (2016) The Perseus computational platform for comprehensive analysis of (prote)omics data. Nat Methods 13: 731740

Vasudevan AAJ, Bahr A, Grothmann R, Singer A, Haussinger D, Zimmermann A, \& Munk C (2018) MXB inhibits murine cytomegalovirus. Virology 522: 158-167

Warner MS, Geraghty RJ, Martinez WM, Montgomery RI, Whitbeck JC, Xu R, Eisenberg RJ, Cohen GH, \& Spear PG (1998) A cell surface protein with herpesvirus entry activity (HveB) confers susceptibility to infection by mutants of herpes simplex virus type 1 , herpes simplex virus type 2 , and pseudorabies virus. Virology 246: 179-189

Whitley R \& Johnston C (2021) Herpes Simplex Viruses: Pathogenesis and Clinical Insights. In Fields Virology: DNA Viruses, Howley PM, Knipe DM, Cohen JL, Damania BA (eds) pp 297-323. Wolters Kluwer Health/Lippincott Williams \& Wilkins; 7th edition (May 17, 2021)

Whitley R \& Roizman B (2016) Herpes Simplex Viruses. In Clinical Virology, Fourth Edition, Richman DD, Whitley RJ, Hayden FJ (eds) pp 415-445. ASM Press

Wolfstein A, Nagel CH, Radtke K, Döhner K, Allan VJ, \& Sodeik B (2006) The inner tegument promotes herpes simplex virus capsid motility along microtubules in vitro. Traffic 7: 227-237

Xie L, Ju Z, Zhong C, Wu Y, Zan Y, Hou W, \& Feng Y (2021) GTPase Activity of MxB Contributes to Its Nuclear Location, Interaction with Nucleoporins and Anti-HIV-1 Activity. Virol Sin 36: 85-94

Zenner HL, Yoshimura S, Barr FA, \& Crump CM (2011) Analysis of Rab GTPase-activating proteins indicates that Rab1a/b and Rab43 are important for herpes simplex virus 1 secondary envelopment. J Virol 85: 8012-8021

Zhang Y \& McKnight JL (1993) Herpes simplex virus type 1 UL46 and UL47 deletion mutants lack VP11 and VP12 or VP13 and VP14, respectively, and exhibit altered viral thymidine kinase expression. $J$ Virol 67: 1482-1492

Zhang Z, Kim T, Bao M, Facchinetti V, Jung SY, Ghaffari AA, Qin J, Cheng G, \& Liu YJ (2011) DDX1, DDX21, and DHX36 helicases form a complex with the adaptor molecule TRIF to sense dsRNA in dendritic cells. Immunity 34: 866-878 
904

905

906

907

908

909

910

911

912

\section{TABLE LEGENDS}

Supplementary Table S1: Host proteins in THP-1 cytosols. Intensity-Based Absolute Quantitation (iBAQ) counts of the host proteins identified in the proteomic analysis of the cytosolic extracts prepared from rested or IFN-induced THP-1 $\phi$ cytosol. Statistical analyses were performed with a Welch's t-test. The following cut-offs were set for differentially-expressed proteins: permutationbased false-discovery rate $\leq 0.05$ and $\mid \log _{2}$ fold-change $\mid \geq 0.5$. The protein groups were filtered to keep only the intensities measured in at least three out of four replicates per condition. Gene Ontology knowledge was used to reference the proteins previously described as induced by interferon.

Supplementary Table S2: Host proteins in capsid-host protein complexes. Intensity-Based Absolute Quantitation (iBAQ) counts of host proteins identified in the $\mathrm{V}_{0.1}, \mathrm{~V}_{0.5}, \mathrm{~V}_{1}$ and $\mathrm{D}$ capsid-host protein complexes assembled in rested or IFN-induced THP-1 $\phi$ cytosol. Statistical analyses were performed with a Welch's t-test. The following cut-offs were set for differentially expressed proteins: permutation-based false-discovery rate $\leq 0.05$ and a $\mid \log _{2}$ fold-change $\geq 1.5 \mid$. The protein groups were filtered to keep only those with intensities measured in at least three out of four replicates, in at least one condition. "Interaction significance" column indicates the proteins considered as specific interactors.

Supplementary Table S3: Viral proteins in capsid-host protein complexes. Intensity-based absolute quantification (iBAQ) counts of HSV- $1\left(17^{+}\right)$Lox viral proteins from isolated $V_{0.1}, V_{0.5}, V_{1}$ and $D$ capsids (A) normalized to the intensity of the major capsid protein VP5, (B) unnormalized LFQ intensities. The viral proteins were filtered to keep only those with intensities measured in at least three out of four replicates, in at least one condition.

Supplementary Table S4: List of Antibodies. mAb: monoclonal antibody. pAb: polyclonal antibody. 


\section{TABLE S4: LIST OF ANTIBODIES}

\begin{tabular}{|c|c|c|c|}
\hline Antigen & Name & $\begin{array}{l}\text { species, } \\
\text { type }\end{array}$ & Source and Reference \\
\hline \multicolumn{4}{|l|}{ HSV-1 proteins } \\
\hline capsid & SY4563 & rabbit pAb & (Döhner et al., 2018) \\
\hline VP5 & NC-1 & rabbit $m A b$ & $\begin{array}{l}\text { Gary Cohen \& Roselyn Eisenberg, University of Pennsylvania, } \\
\text { Philadelphia, USA; (Cohen, G. H. et al., 1980) }\end{array}$ \\
\hline \multicolumn{4}{|l|}{ Host proteins } \\
\hline nuclear pore & mAb414 & mouse mAb & ab24609, Abcam \\
\hline p230 & p230 & mouse mAb & 611280, BD Biosciences \\
\hline E-cadherin & $\begin{array}{c}\alpha-E- \\
\text { cadherin }\end{array}$ & mouse mAb & C37020;610404, BD Transduction Laboratories \\
\hline calnexin & $\alpha$-calnexin & rabbit pAb & Ari Helenius, ETH Zürich, Switzerland; (Hammond \& Helenius, 1994) \\
\hline Tom20 & $\mathrm{F}-10$ & mouse mAb & Sc-17764, Santa Cruz Biotechnology \\
\hline GAPDH & $14 C 10$ & rabbit $p A b$ & 2118S, Cell Signaling (NEB) \\
\hline $\mathrm{MxA} / \mathrm{MxB}$ & M143 & mouse mAb & (Flohr et al., 1999) \\
\hline$M \times A$ & $\alpha-M \times 1$ & rabbit $\mathrm{pAb}$ & ab207414, Abcam \\
\hline $\mathrm{MxB}$ & $\alpha-M \times 2$ & rabbit $\mathrm{pAb}$ & NBP1-81018, Novus Biological \\
\hline FLAG & ANTI-FLAG & rabbit $\mathrm{pAb}$ & F7425, Sigma-Aldrich \\
\hline
\end{tabular}

930 


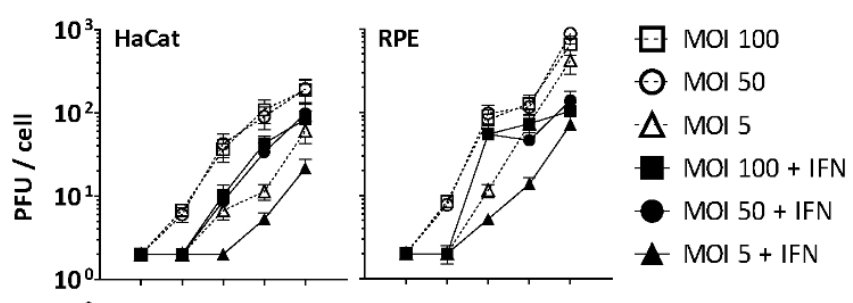

934 Figure 1: IFN restricts HSV-1 infection in keratinocytes, epithelial cells, and macrophages. HaCat, $\mathrm{RPE}, \mathrm{M} \phi$, or $M \phi_{\mathrm{R}}$ cells were mock-treated or treated with human IFN- $\alpha(1000 \mathrm{U} / \mathrm{mL})$ for $16 \mathrm{~h}$ and were infected with HSV-1(17 $)$ Lox at $2.5 \times 106$ (MOI 5), $2.5 \times 107$ (MOI 50), or $5 \times 107 \mathrm{PFU} / \mathrm{mL}$ (MOI $100)$, and the amount of cell-associated and extracellular virions was titrated on Vero cells. Each data point represents the mean of the three technical replicates of the combined cell-associated and extracellular titers. The error bars represent the standard deviation. 


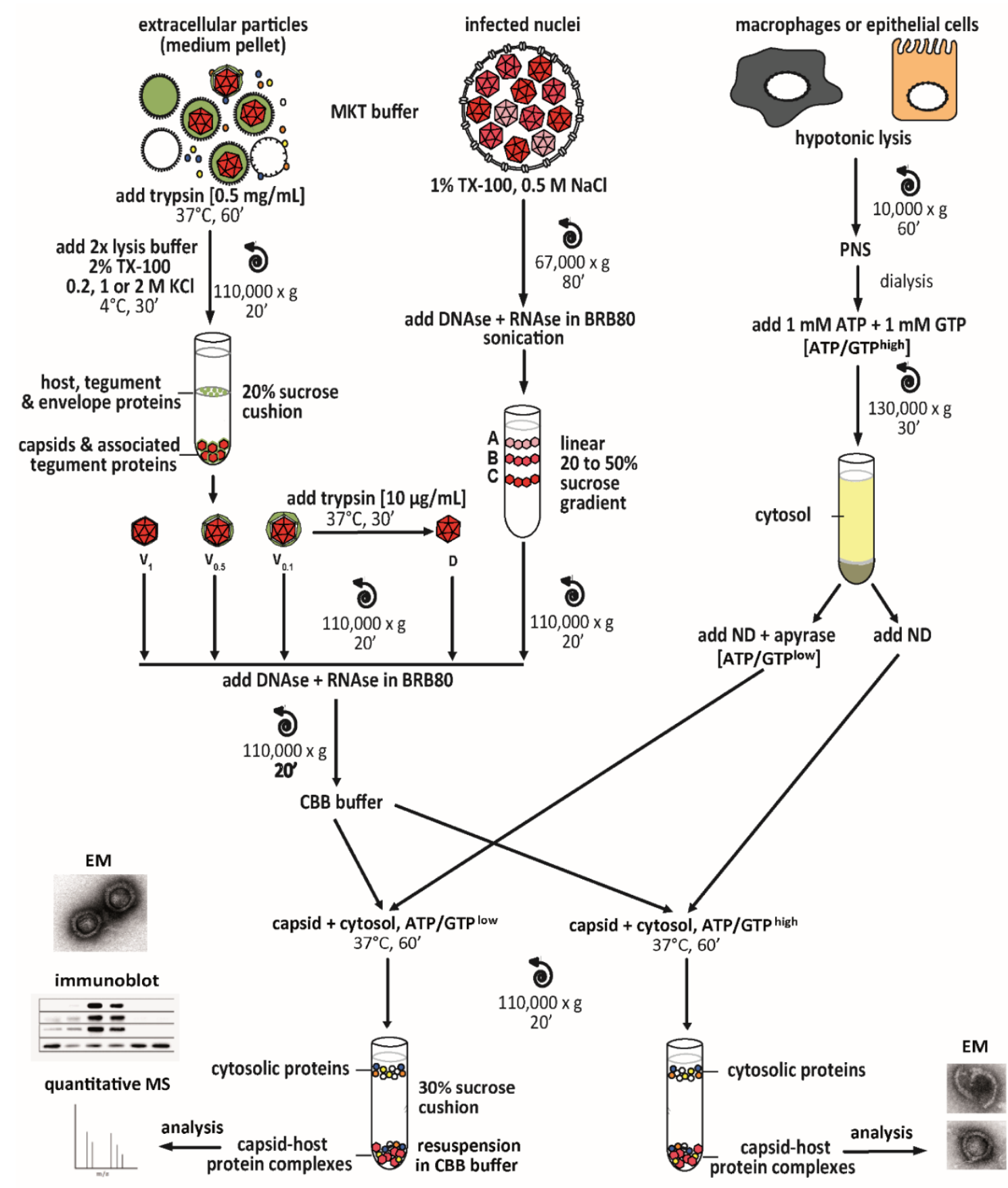
Tegumented viral $V_{0.1}, V_{0.5}$, or $V_{1}$ capsids (red) were isolated from extracellular particles released from BHK-21 cells infected with HSV-1 $\left(17^{+}\right)$Lox. They were lysed in $1 \%$ Triton X-100 to solubilize the viral envelope, and to extract different amounts of tegument (green) in the presence of $0.1 \mathrm{M}, 0.5 \mathrm{M}$ or $1 \mathrm{M} \mathrm{KCl}$. $\mathrm{D}$ capsids were generated from $\mathrm{V}_{0.1}$ capsids by mild trypsin digestion. These different capsid types were purified through sucrose cushions. Tegument-free nuclear $A, B$, and $C$ capsids were isolated from the nuclei of BHK cells infected with HSV-1 $\left(17^{+}\right)$Lox by gradient sedimentation. The capsids were resuspended in BRB80 buffer, treated with benzonase to degrade DNA and RNA, sedimented again, and incubated with cytosol fractions (yellow) from control or IFN-induced macrophages (THP-1 $\phi$ ) or epithelial A549 cells. After sedimentation through sucrose cushions, the capsid-host protein complexes were analysed by mass spectrometry (MS), immunoblot, or electron microscopy (EM). PNS, post-nuclear-supernatant; ND, nocodazole. 


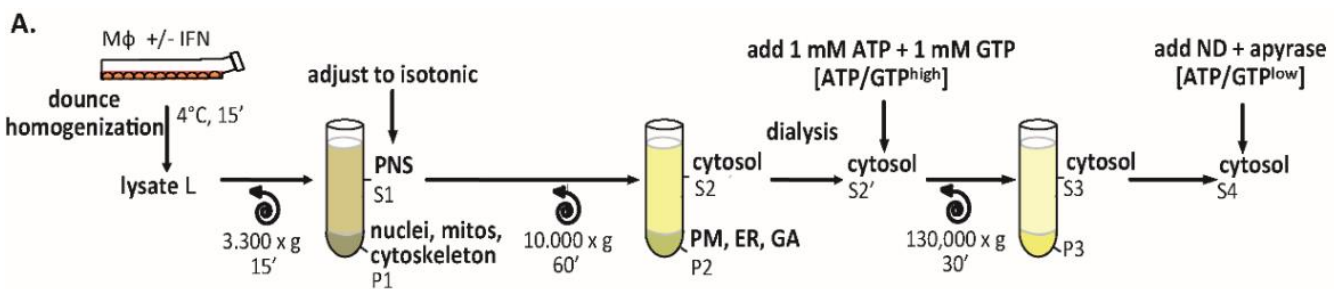

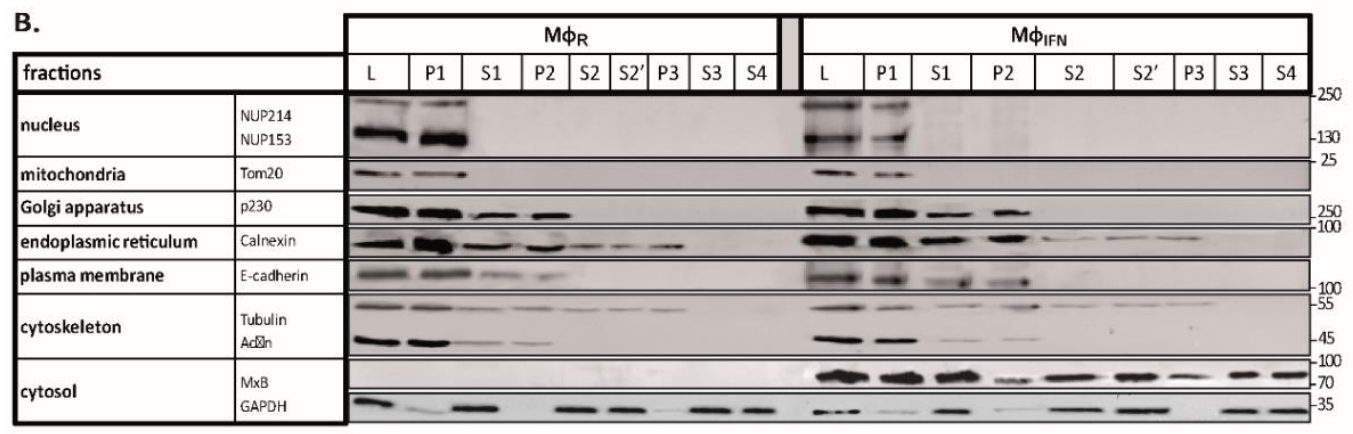

c.
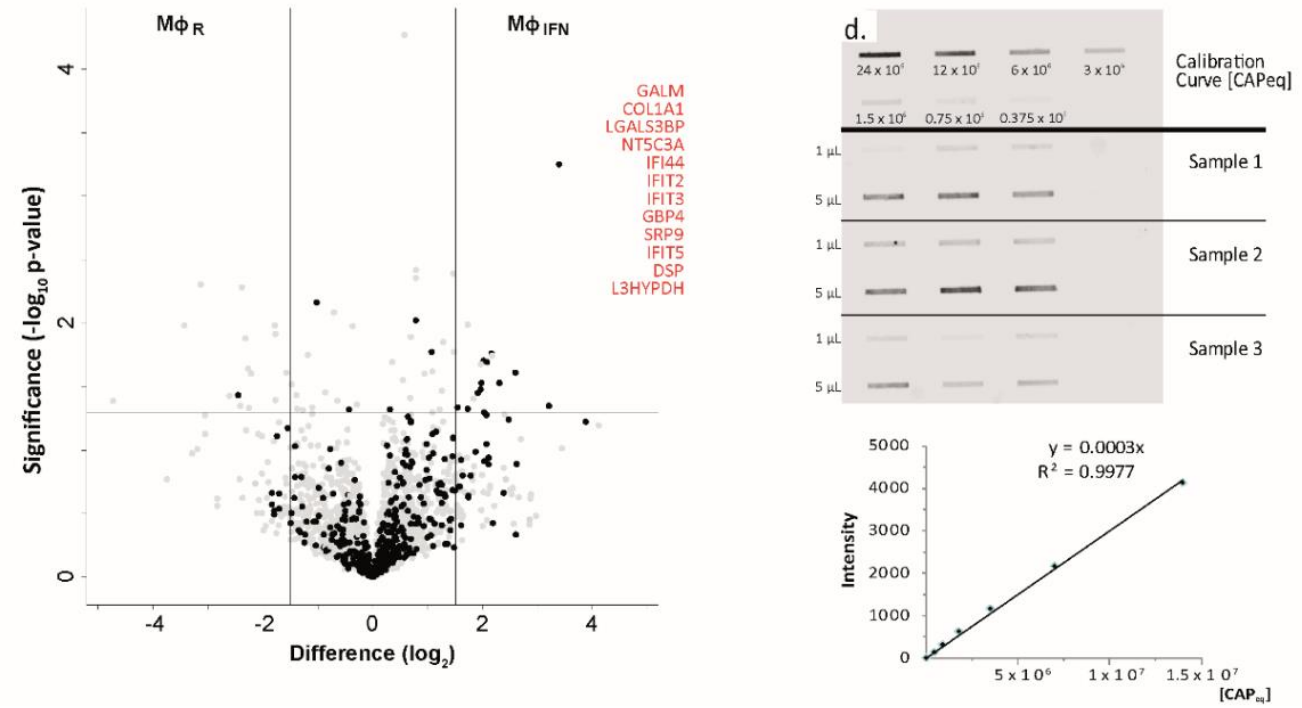

Supplementary Figure S2: Characterization of cytosolic extracts and calibration of capsids. (A) Cytosols were prepared from rested $M \phi_{\mathrm{R}}$ or IFN-induced $M \phi_{\mathrm{IFN}}$ macrophage cells. After swelling in hypotonic buffer, the cells were homogenized (L), and nuclei and mitochondria were sedimented (P1). The post-nuclear supernatant (S1) was adjusted to isotonic salt concentration, and centrifuged to sediment membrane compartments (P2), like the PM, ER and GA. To control the nucleotide concentration, the cytosols (S2) were dialyzed against a $7 \mathrm{kDa}$ membrane prior to the addition of an ATP regeneration system ( $\left(2^{\prime}\right)$. The remaining actin filaments and microtubules were sedimented in P3 to obtain a soluble cytosol fraction (S3). To reduce ATP and GTP levels, some cytosols were treated with $10 \mathrm{U} / \mathrm{mL}$ of apyrase (S4). Nocodazole (ND) was added to prevent polymerization and sedimentation of microtubules. (B) All fractions generated were analysed by immunoblot for the respective compartment marker proteins as indicated. Nup, nucleoporins. (C) Volcano plot summarizing the effect of IFN induction on the cytosol proteome. ISGs associated with the interferomeDB were enriched in cytosol from $M \phi_{\mathrm{IFN}}$ as compared to $M \phi_{R}$ with an FDR of $7.96 \times 10^{-7}$ and an FC $\geq 2$ in at least 1 experiment (Fisher's exact test). IFN-inducible proteins are indicated by black circles, and those with an abundance $\log _{2}$ difference $\geq 1.5$ (vertical lines), and an uncorrected $p$ value $<0.05$ (horizontal line) are labelled in red. (D) The slot blot used for the estimation of capsid concentrations (capsids equivalent; $\mathrm{CAP}_{\text {eq }}$ ) of all preparations was labeled with anti-capsid antibodies (rabbit pAb SY4563) and adjusted to a calibration curve of a standard preparation. 

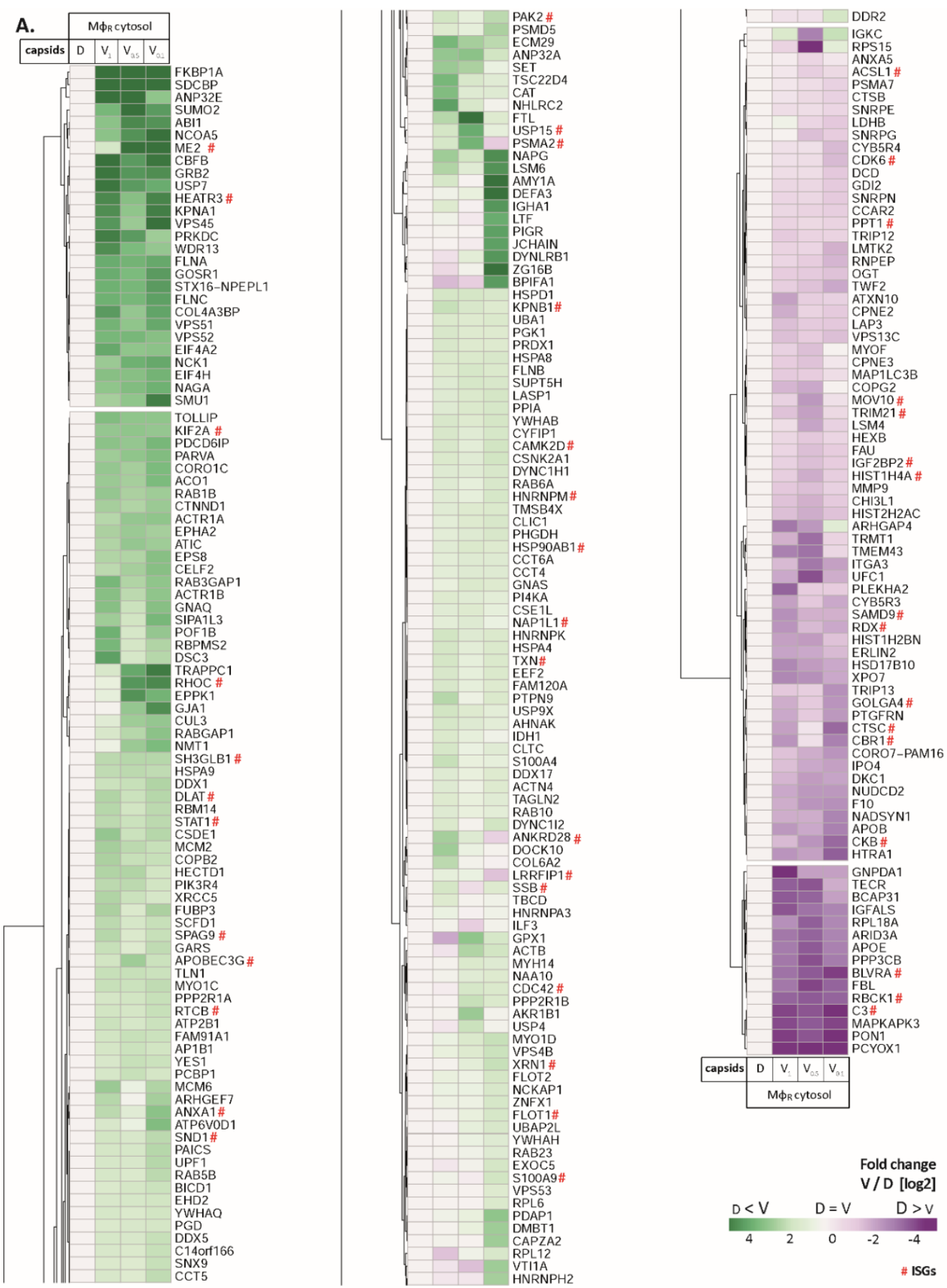

973 Supplementary Figure S3A: HSV-1 capsids interactomes. Unbiased hierarchical clustered heat map showing the $\log _{2}$ fold changes of host proteins identified from capsids-host protein sediments (c.f. Fig. 2; abundance $\log _{2}$ difference larger than 1; significance permutation-based FDR smaller than 0.05 ) from ( $A$ ) cytosol of resting $M \phi$, or (B) IFN-induced $M \phi_{\text {IFN }}$ macrophages. For each protein, the fold change was calculated based on their abundance (iBAQs) in $V_{1}, V_{0.5}$, or $V_{0.1}$ capsids compared to $D$ capsids using a linear scale from violet being the lowest to dark green being the highest. 
B.
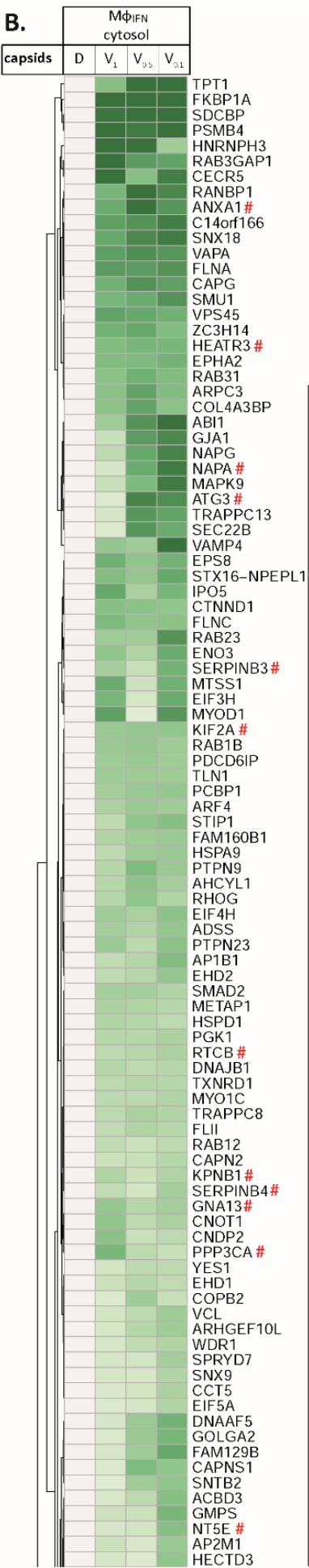

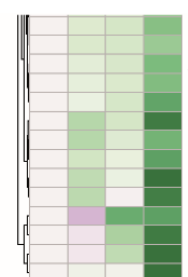

S100A9\# DCP1A\# ATP6VOD1 GUSB SYALA2 SEC24C NUDT2
LIMS1 LIMS1
PEPD
RPLP2 RPL34\#
DCPS SH3GLB1\# SND1\#
VPS4B VPS4B
SIPA1L3 SIPA1L23 PPIA CUL3 NCKAP AlMP2 GBF1
CSNK2B YWNK2B PLEC CFL1
S100A4 S100A4
VPS35 VPS35
DDX6
TNPO1 DDX6
TNPO1
EEF3D\# RARS USP9X CNN3 FLNB GRB2
CLIC1
GARS CCT4 EEF2 GAPDH CSNK1A IPO7 COPS 3

UPF1

TGM2\#

PSMA1
CSE1L
CORO1C CORO1C PRKAR2A
COG7 PDCD5 HUWE1 EXOC4
SCFD1
USP7
SET USP7 SET
ADAR \# MARK2 MAGOHB ARL2 XRCC5
ANP32B ANP32B
PDCD6 HNRNPF HNRNPM
XRCC6 ANP32A TPP2 CALR ANKRD28\# DFFA KCTD12 RABEP1 RBCK1\# HIST3H2BB GBA CYFIP DCLK1 P4HB EXOC1 ECM29 HNRNPL OLA SNX WNK1 AXL\# SHARPIN PDIA4 ARAP1 STK4 \#
PPP6R1

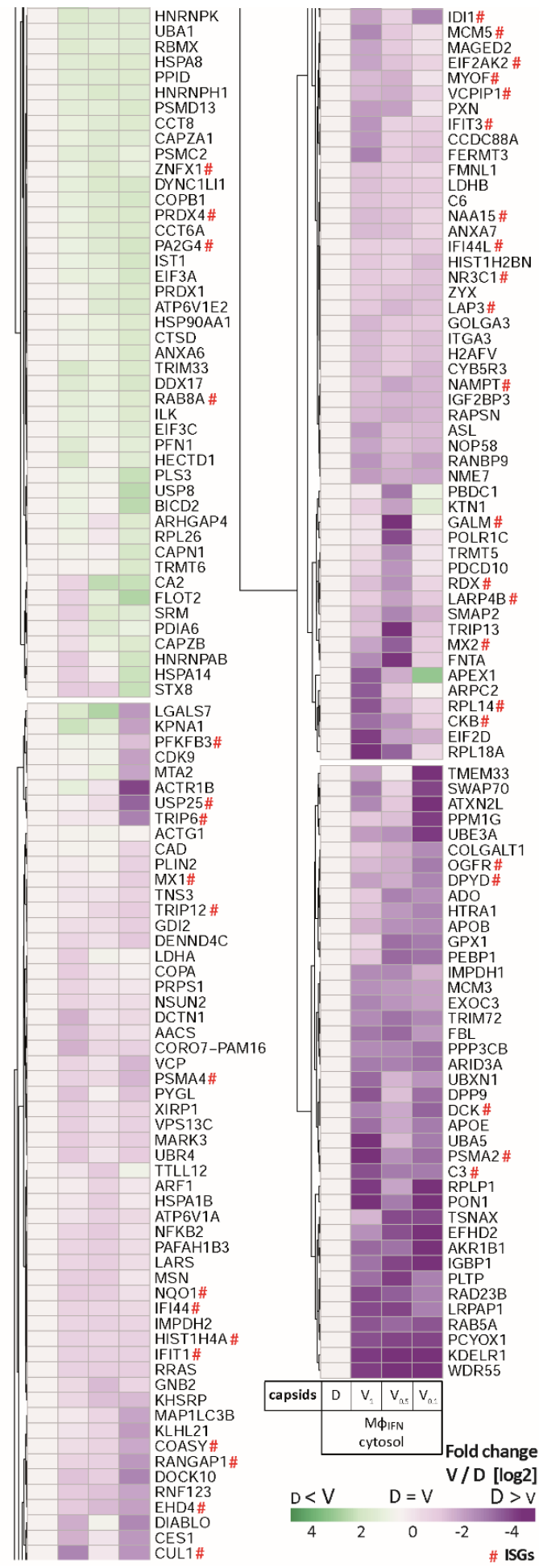

Supplementary Figure S3B: HSV-1 capsids interactomes. Unbiased hierarchical clustered heat map showing the $\log _{2}$ fold changes of host proteins identified from capsids-host protein sediments (c.f. Fig. 2; abundance $\log _{2}$ difference larger than 1 ; significance permutation-based FDR smaller than $0.05)$ from $(A)$ cytosol of resting macrophages $\left(M_{\phi}\right)$, or (B) IFN-induced macrophages $\left(M_{\text {申IFN }}\right)$. For each protein, the fold change was calculated based on their abundance (iBAQs) in $V_{1}, V_{0.5}$, or $V_{0.1}$ capsids compared to $\mathrm{D}$ capsids using a linear scale from violet being the lowest to dark green being the highest. 

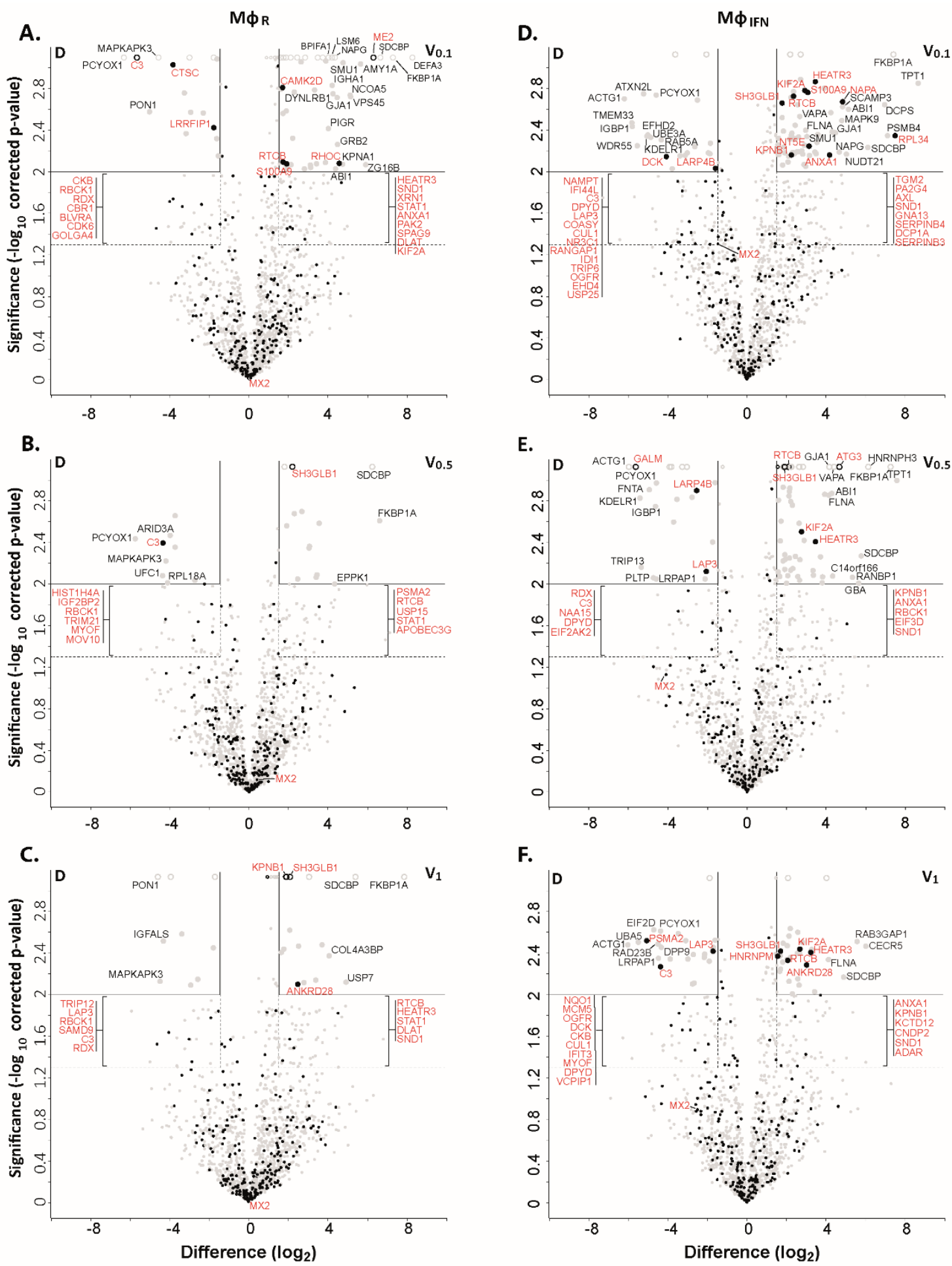

Figure 2: Cytosolic IFN-induced macrophage proteins binding to HSV-1 capsids. Volcano plots of iBAQs counts of proteins identified in capsid-host protein complexes assembled in cytosol from resting THP-1 $\phi$ cells $(A-C)$ or treated with interferon- $\alpha(D-F)$ using $V_{0.1}(A, D), V_{0.5}(B, E)$, or $V_{1}(C, F)$ capsids in comparison to $D$ capsids. Proteins identified as highly specific interactions are indicated with larger symbols ( $\log _{2}$ difference: 1.5 ; Welch's t-test, two-tailed, permutation-based FDR $\leq 0.01$ ); those with a $\log _{2}$ difference $\geq 4$ are annotated. ISGs (interferome.org) are indicated by filled black circles, and are annotated in red if significantly enriched (permutation-based FDR $\leq 0.05$, and $\log _{2}$ difference $\geq 1.5$ ). Proteins with a q-value $=0$ were imputed to $-\log _{10} q$-value $=3.1$ (maximum of the graph), and were indicated with empty circles. 

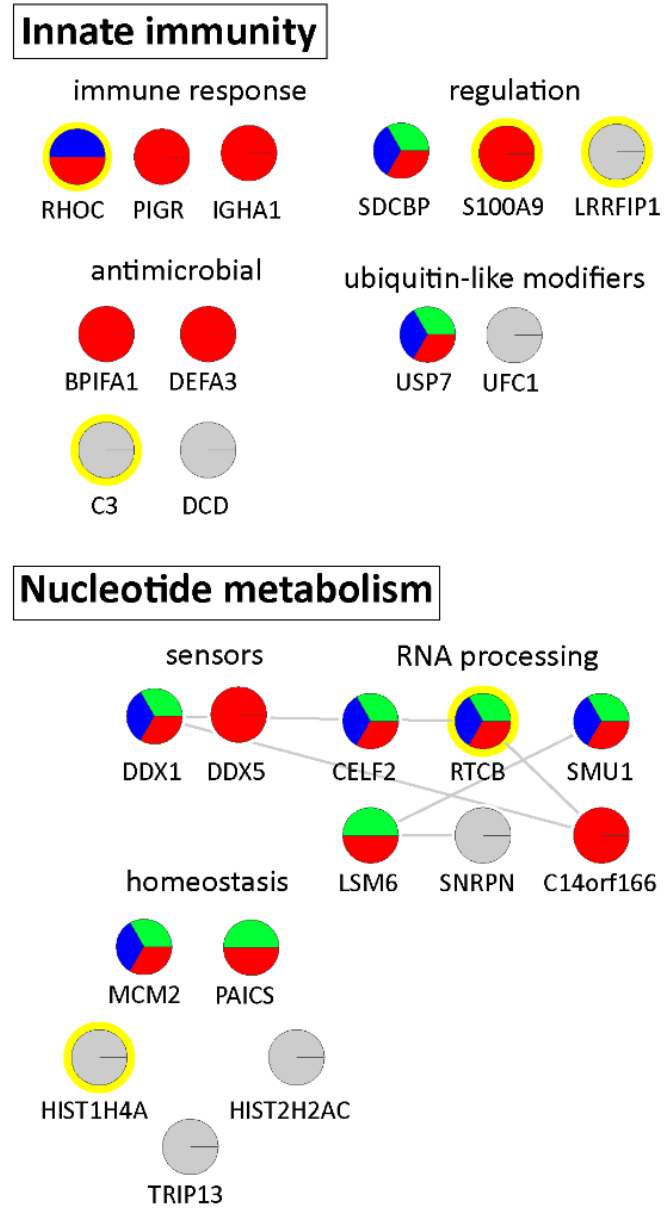

\section{Protein metabolism}

regulation of
gene expression protein synthesis

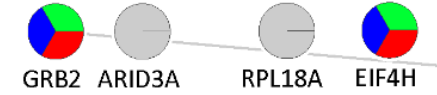

others

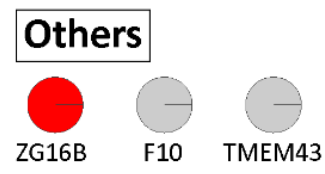

CORO7-PAM16

\section{Transport}

cytoskeleton organisation
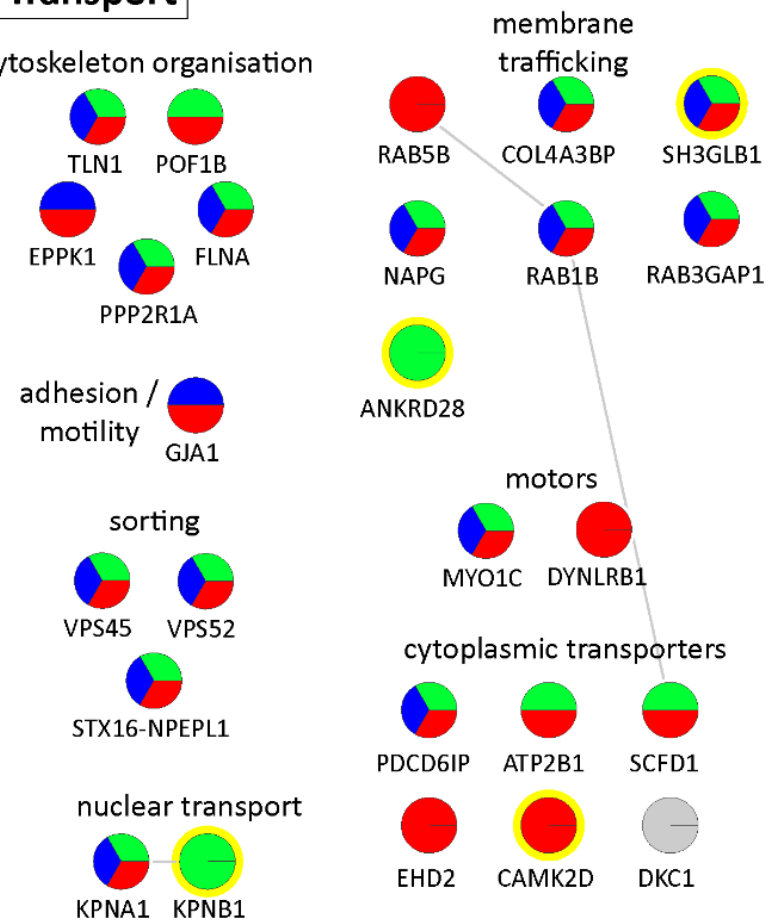

\section{Signaling}

Signal transduction

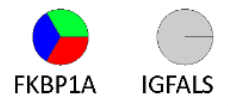

proliferation / survival
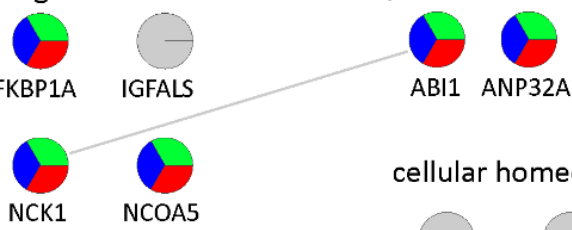

cellular homeostasis

MAPK/ERK signaling

PCYOX1 PON1

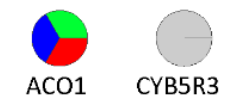

carbon metabolism
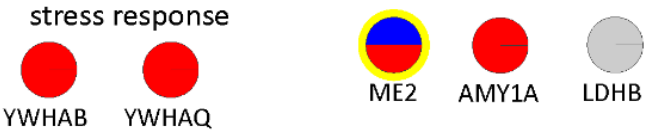

MAPKAPK3

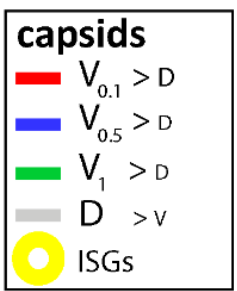

Supplementary Figure S4: Cytosolic proteins of resting macrophage binding to HSV-1 capsids. Host proteins from cytosol of resting $M \phi$ (c.f. Fig. 3A, 3B, 3C; abundance $\log _{2}$ difference larger than 1.5; significance permutation-based FDR smaller than 0.05 ) interacting with $\mathrm{V}_{0.1}, \mathrm{~V}_{0.5}, \mathrm{~V}_{1}$, or D capsids were assembled into a functional interaction network of known protein-protein-interactions (grey lines; STRING database, confidence score of 0.7), and grouped according to their known functions (Gene Ontology, Pathway analysis). The Pie chart for each protein indicates its relative enrichment on $\mathrm{V}_{0.1}$ (red), $\mathrm{V}_{0.5}$ (blue), $\mathrm{V}_{1}$ (green), or $\mathrm{D}$ capsids (grey). 


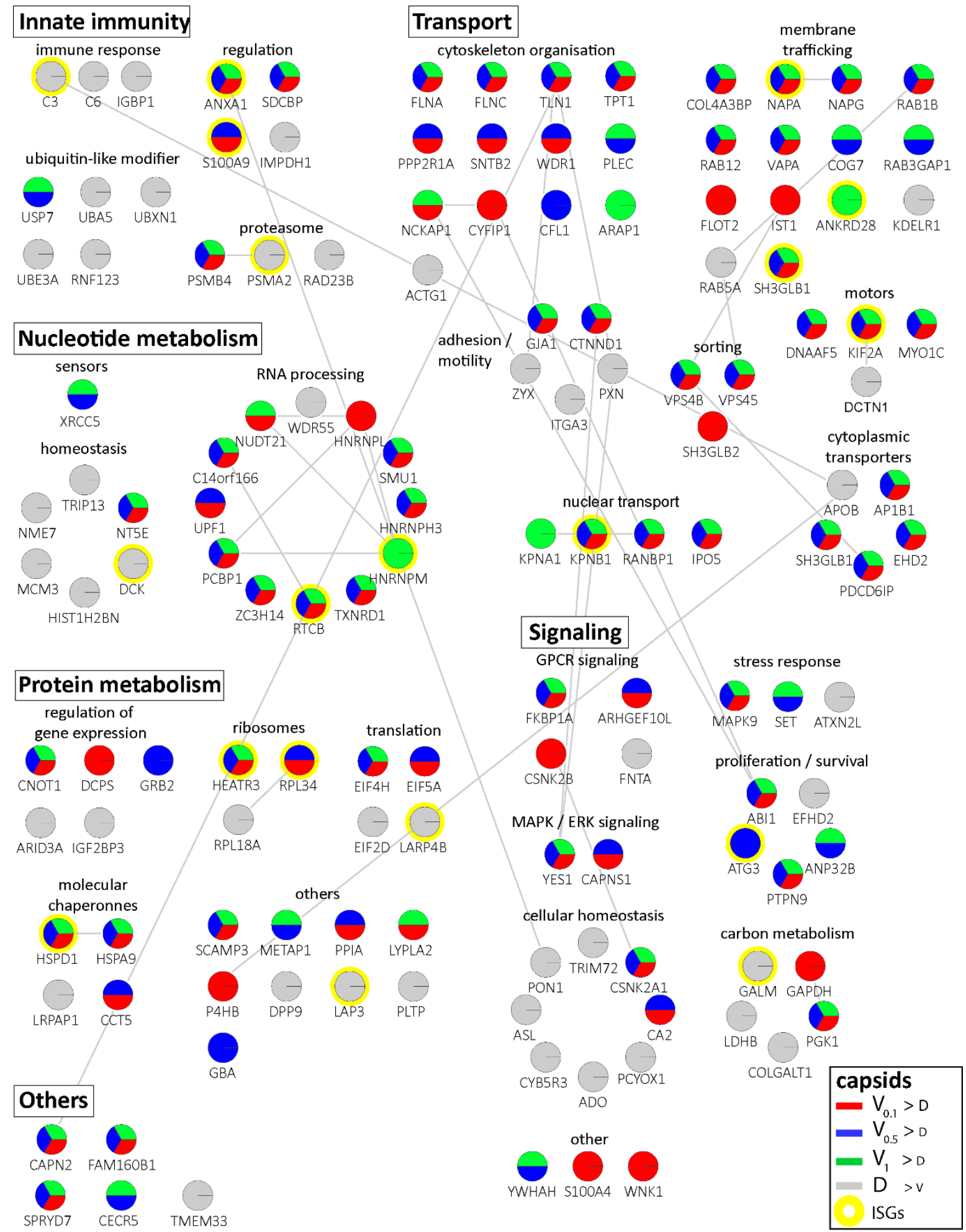

Figure 3: Cytosolic proteins of IFN-induced macrophages binding to HSV-1 capsids. Host proteins from cytosol of IFN-stimulated $M \phi_{\text {IFN }}$ (c.f. Fig. 3D, 3E, 3F; abundance $\log _{2}$ difference larger than 1.5; significance permutation-based FDR smaller than 0.05 ) interacting with $\mathrm{V}_{0.1}, \mathrm{~V}_{0.5}, \mathrm{~V}_{1}$, or $\mathrm{D}$ capsids were assembled into a functional interaction network of known protein-protein-interactions (grey lines; STRING database, confidence score of 0.7), and grouped according to their known functions (Gene Ontology, Pathway analysis). The Pie chart for each protein indicates its relative enrichment on $\mathrm{V}_{0.1}$ (red), $\mathrm{V}_{0.5}$ (blue), $\mathrm{V}_{1}$ (green), or $\mathrm{D}$ capsids (grey). 
A.

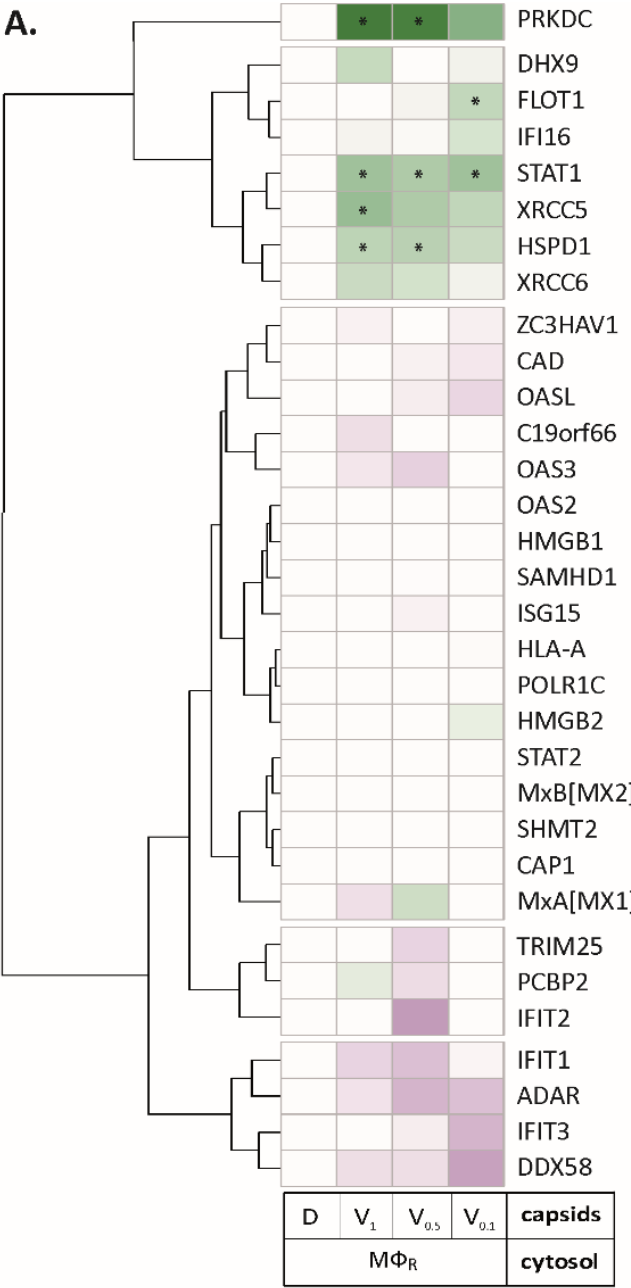

B.

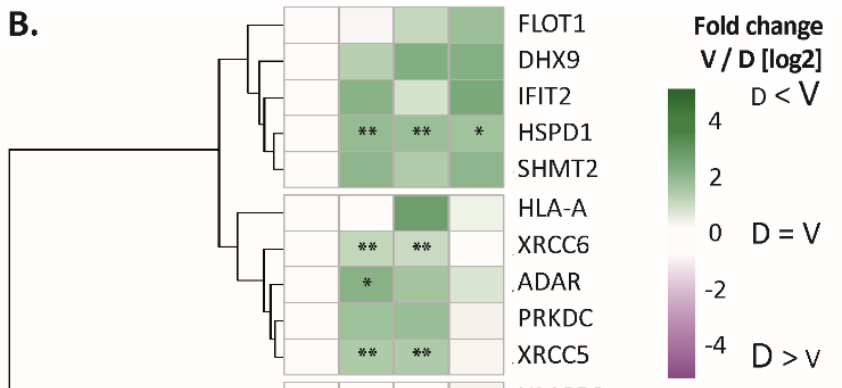

1014 Figure 4: HSV-1 capsids associate with proteins involved in type I IFN response. Unbiased hierarchical clustered heat map showing the $\log _{2}$ fold changes of IFN-induced proteins (GO type-I IFN) identified from capsids-host protein sediments from cytosol of resting $M \phi$, or IFN-induced $M \phi_{\text {IFN }}$ macrophages. For each protein, the fold change was calculated based on their abundance (iBAQs) in $V_{1}, V_{0.5}$ and $V_{0.1}$ capsids as compared to their abundance in $D$ capsids, using a linear scale from violet being the lowest to dark green being the highest. $\left({ }^{*}\right)$ and $\left({ }^{* *}\right)$ design the proteins with an FDR corrected $p$-value $<0.05$ and $<0.01$, respectively. 


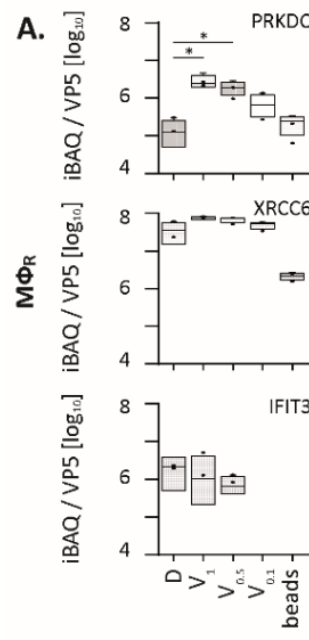

B.
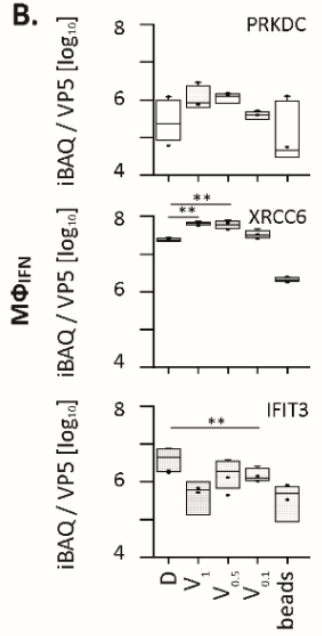

C. $\underset{2}{2} 87 \quad$ PRKDC
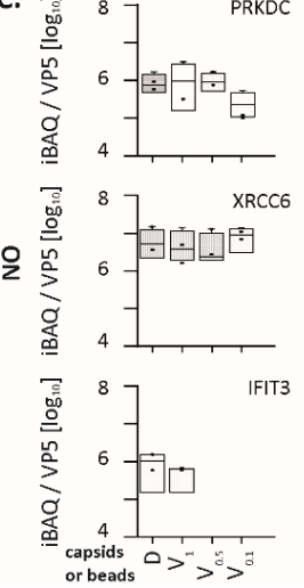
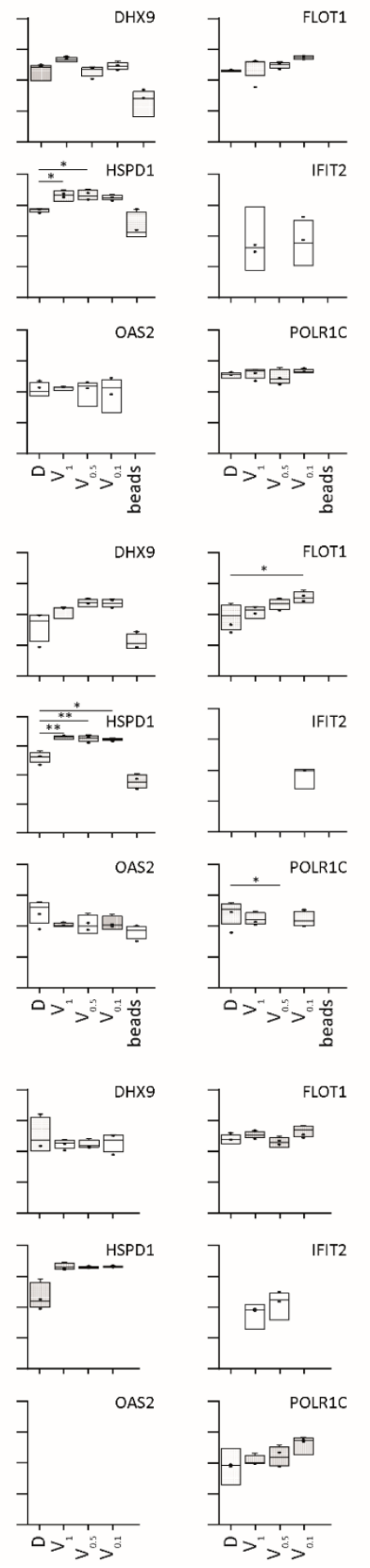
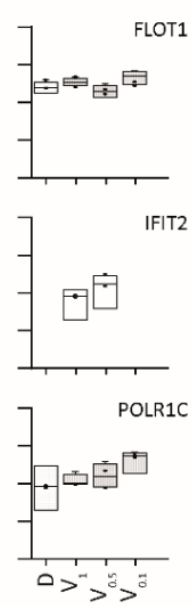
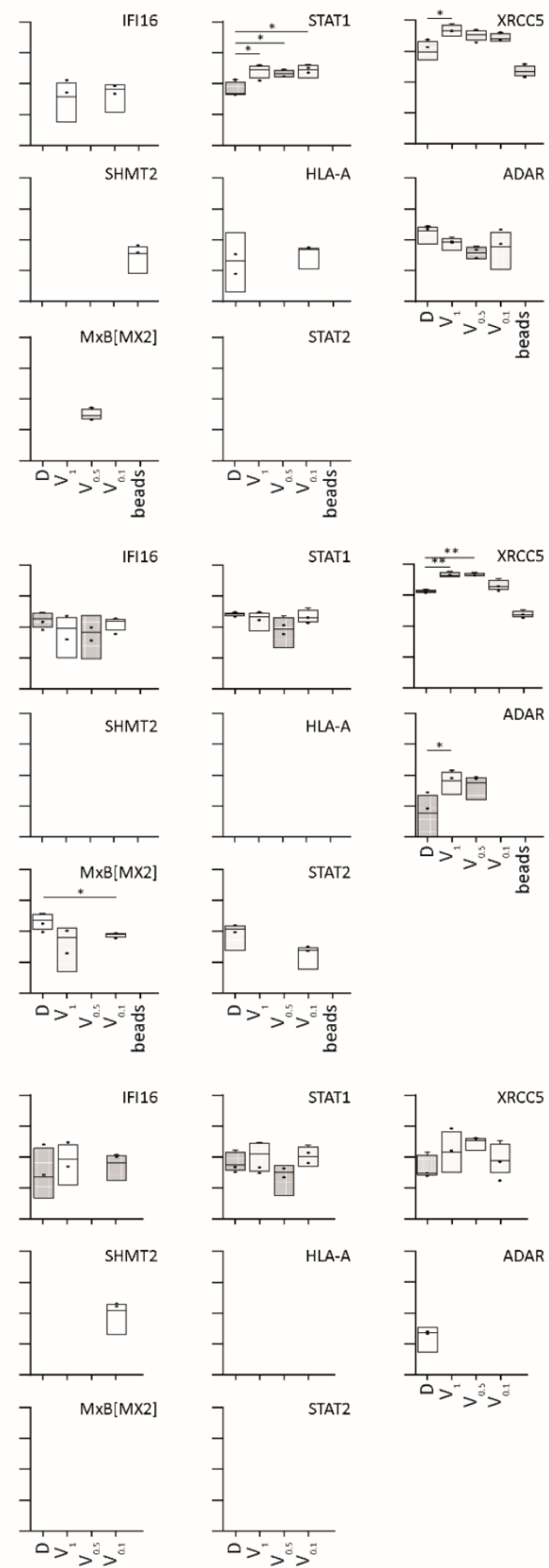

Supplementary Figure S5: HSV-1 capsids binds to a few ISG proteins. Box and whisker plot of iBAQs showing the differential detection of PRKDC, DHX9, FLOT1, IFI16, STAT1, XRCC5, XRCC6, HSPD1, IFIT2, SHMT2, HLA-A, ADAR, IFIT3, OAS2, POLR1C and MX2 in D, $\mathrm{V}_{1}, \mathrm{~V}_{0.5}$ and $\mathrm{V}_{0.1}$ capsids-host protein sediments after incubation in (A) cytosol of resting M $\phi R$ macrophages, (B) IFN-induced M $\phi I F N$ macrophages or (C) no cytosol. $\left(^{*}\right)$ design the significant binding to D or V0.1, V0.5 and V1 capsids as assessed by Welch's t-test (two-tailed, permutation-based FDR $\leq 0.05$ ) comparing $D$ vs $V_{0.1}, V_{0.5}$ or $V_{1}$ capsids in each cytosol separately. 


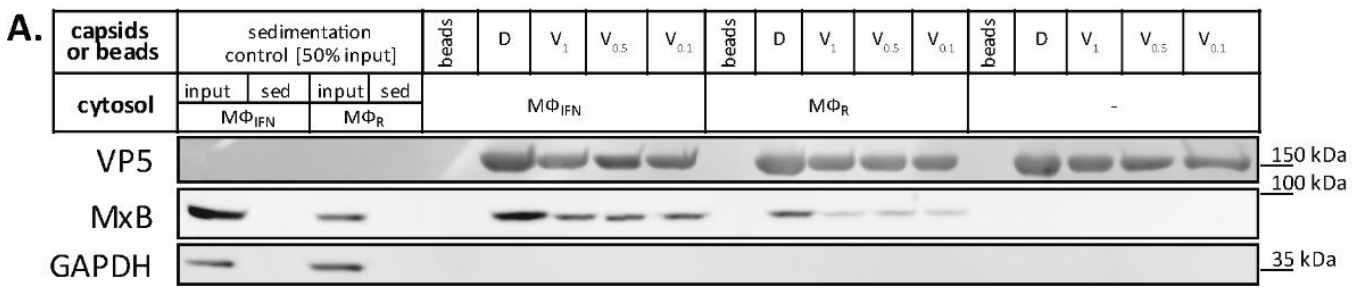

B.
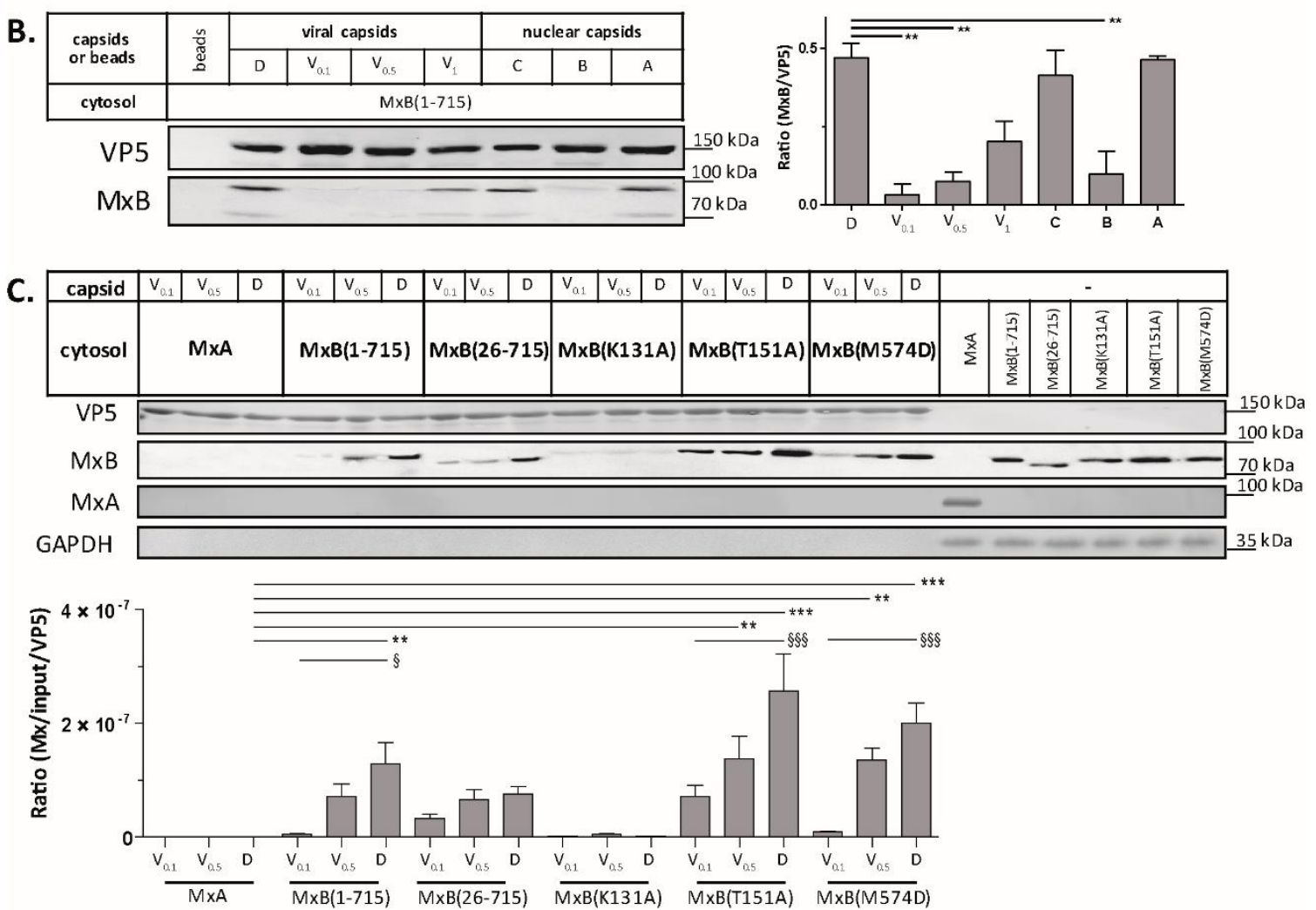

1030 Figure 5: Tegumentation reduces MxB binding to HSV-1 capsids. The binding of MxB to viral $V_{0.1}$, $V_{0.5}, V_{1}$ or $D$, or to nuclear $A, B$ or $C$ capsids was analysed after incubation in $0.2 \mathrm{mg} / \mathrm{mL}$ cytosol prepared from (A) THP-1 $\phi$ stimulated or not with IFN, or (B-C) A549 cells stably expressing MxA, $M \times B(1-715)$ full length, the short $M \times B(26-715)$, or $M \times B$ mutants defective in GTP-hydrolysis $\mathrm{MxB}(\mathrm{T151A})$, GTP-binding and hydrolysis $\mathrm{MxB}(\mathrm{K} 131 \mathrm{~A})$, or dimerization $\mathrm{MxB}(\mathrm{M} 574 \mathrm{D})$. Sedimented capsid-host protein complexes were then analysed by immunoblot for VP5 (capsid), MxB, MxA and GAPDH as a loading control. As control cytosols were sedimented without capsids (A: sed), or with uncoated agarose beads ( $\mathrm{A}, \mathrm{B}$ : beads). The amounts of $\mathrm{M} \times \mathrm{A} / \mathrm{M} \times \mathrm{B}$ found in the capsid-host protein complexes were quantified, and normalized to their respective VP5 levels. Error bars: SEM. summarized from three experiments. One asterisk denotes $p<0.05$, two asterisks indicate $p<0.01$ and three asterisks represent $p<0.001$ as determined by Welch's t-tests comparisons.

Figure 5A-source data 1-3. Figure 5B-source data 1-3. Figure 5C-source data 1-5. Full western blot quantifications. 
bioRxiv preprint doi: https://doi org/10.1101/2022.01.25.477704 - this version posted January 27, 2022. The copyright holder for this preprint (which was not certified by peer review) is the author/funder, who has granted bioRxiv a license to display the preprint in perpetuity. It is made available under aCC-BY 4.0 International license.

A.

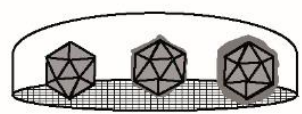

Adsorb capsids on EM grids

Bi.

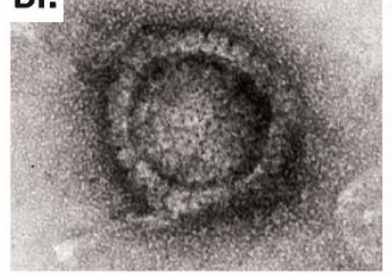

$\mathrm{Ci}$.
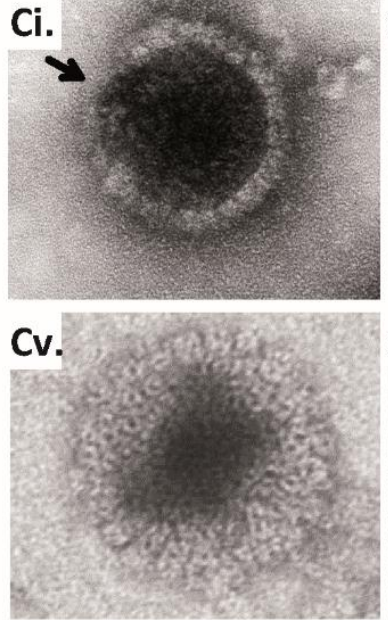

Di.
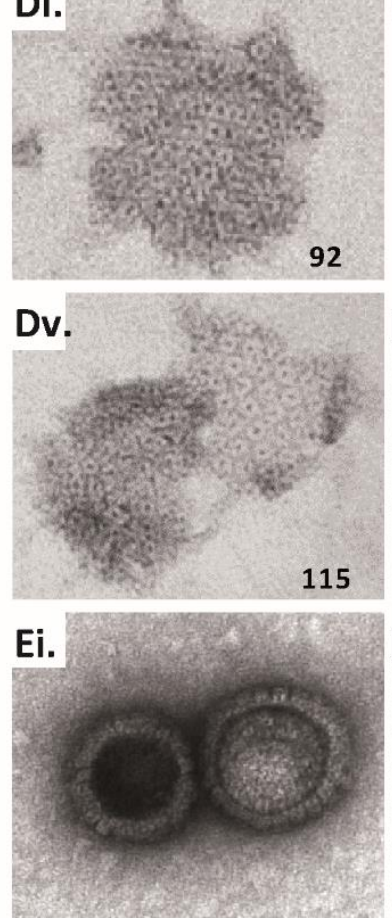

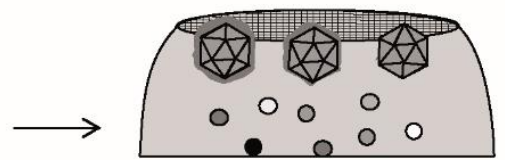

Incubate capsids

in cytosol
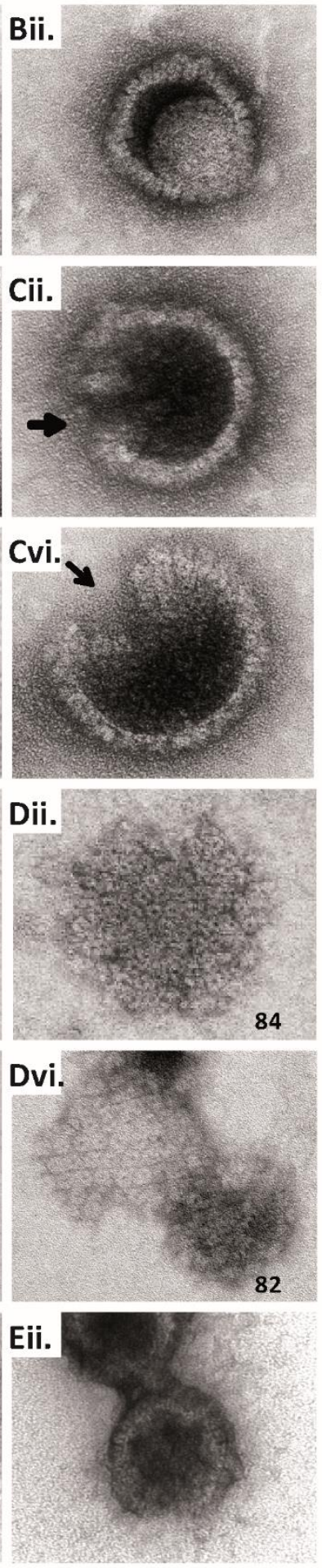
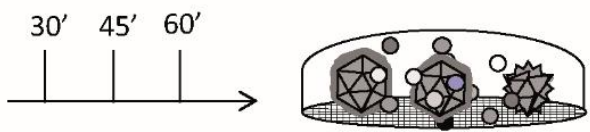

Negative stain and EM
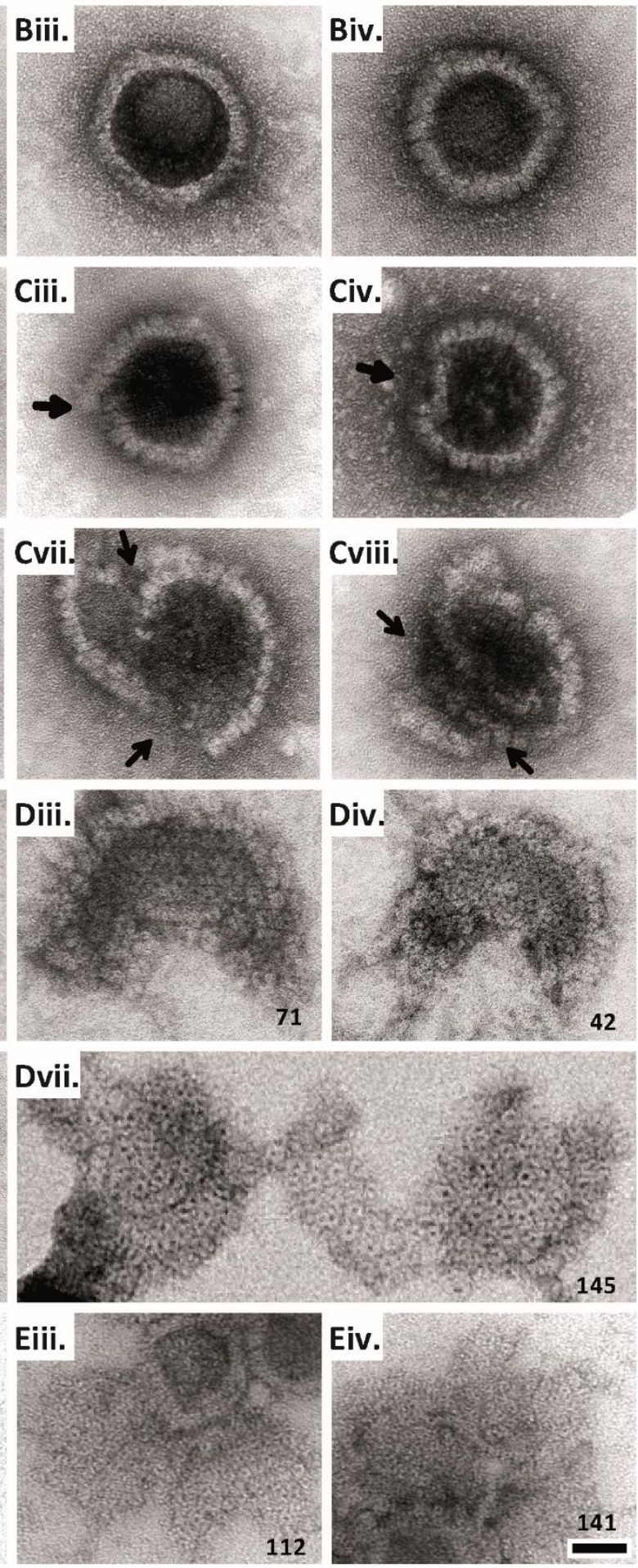

Figure 6: MxB induces disassembly of herpesviral capsids. (A) Experimental design: Capsids were adsorbed onto hydrophilic enhanced carbon-coated EM grids for $20 \mathrm{~min}$ at RT. The capsids were incubated in cytosol with ATP/GTP high, and the incubation was stopped at different times by extensive washing. The samples were analysed by EM after negative staining with uranyl acetate. (B-D) Capsids 
A549 expressing cells for $1 \mathrm{~h}$ at $37^{\circ} \mathrm{C}$, and classified as (B) intact, (C) punched or (D) disassembled flat phenotypes. The number of capsomers per flat particle was counted, and is displayed at the bottom of each figures. $(E)$ Nuclear VZV capsids remain intact (Ei) after incubation in the cytosol of A549 control cells, or but appear punched (Eii) or as flat shells (Eiii, Eiv) after incubation in the cytosol of A549 cells expressing MxB. Scale bar: $50 \mathrm{~nm}$.
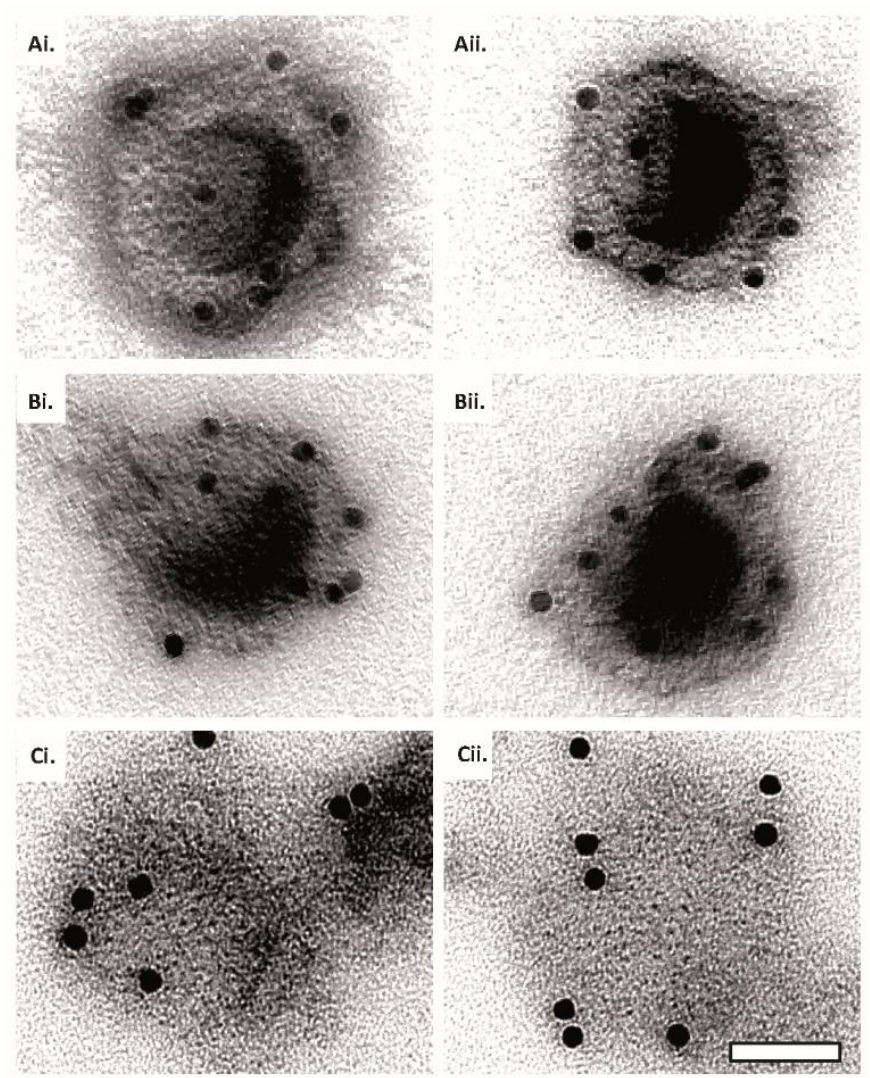

Supplementary Figure S6: Capsid disassembly intermediates by anti-capsid immunoEM. Images of capsids after negative staining and labelling with antibodies raised against the major capsid protein VP5 (NC-1), after incubation in ATP-complemented cytosol from A549 control or MxB(1-715) expressing cells for $60 \mathrm{~min}$ at $37^{\circ} \mathrm{C}$, and classified as (A) intact, (B) punched, or (C) flattened shells. Scale bar: $50 \mathrm{~nm}$. 

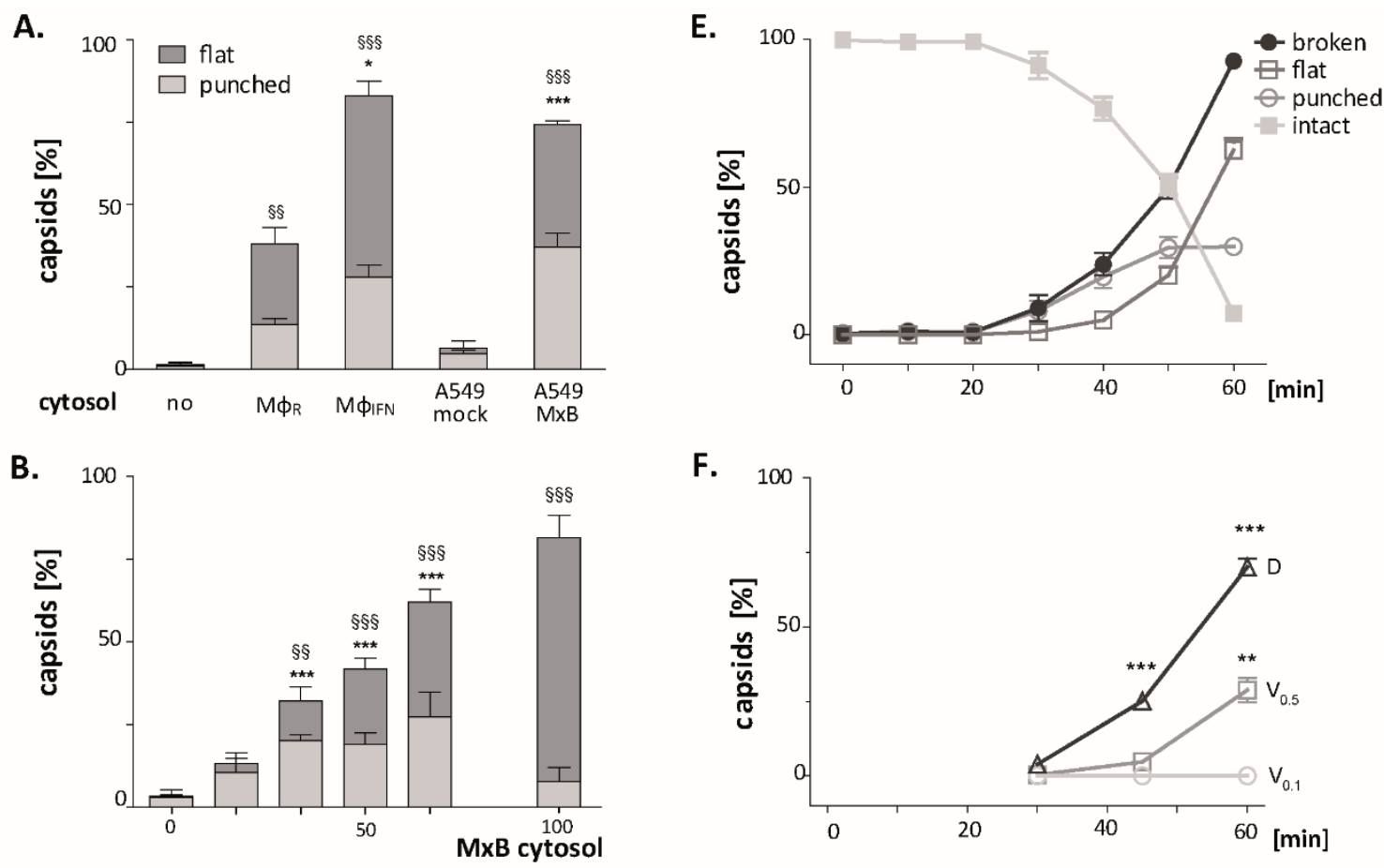

[\%]
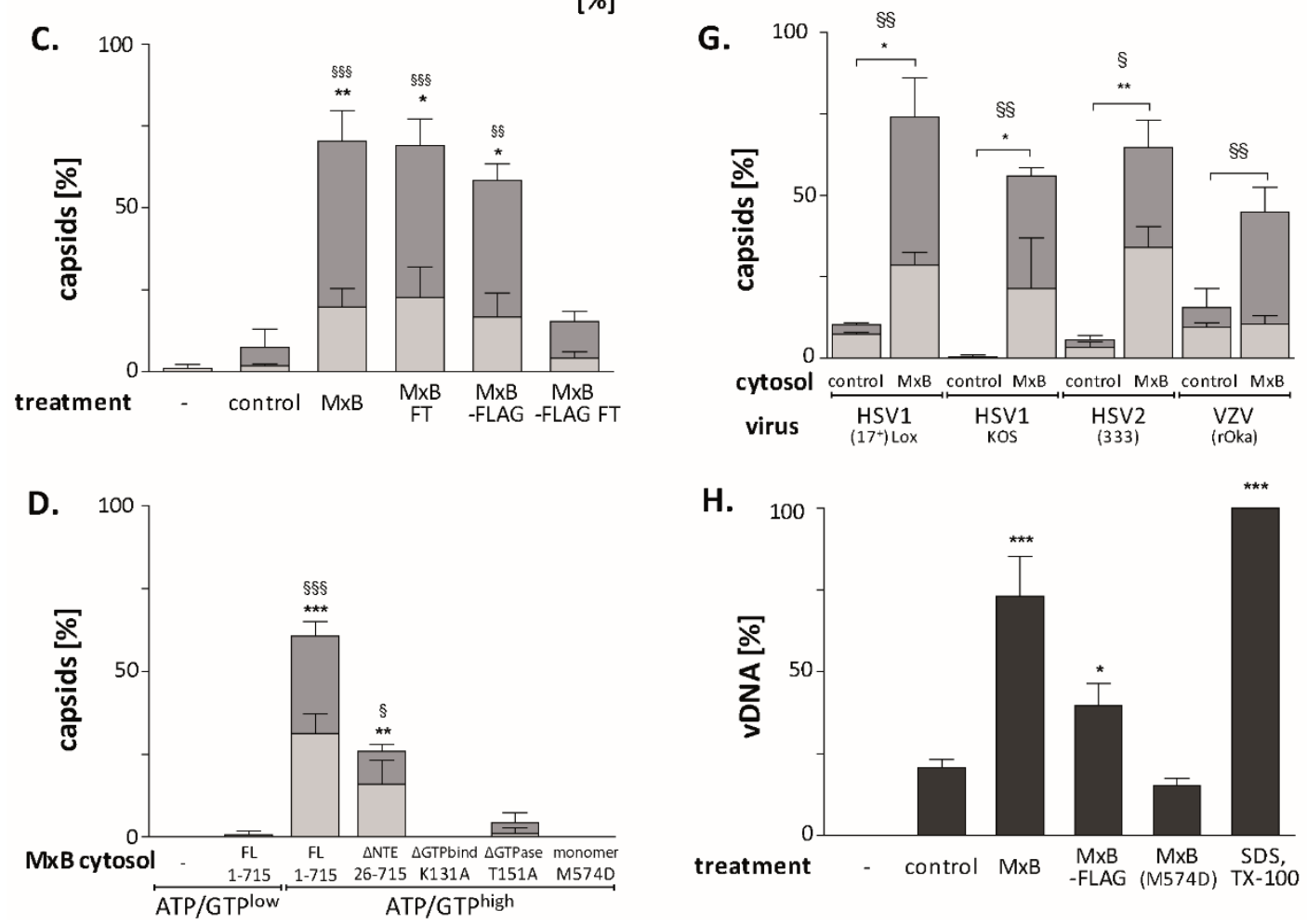

Figure 7: MxB GTP hydrolysis and dimerization required for capsid disassembly and vDNA release of viral genomes. HSV-1 (A-H), HSV-2 (G) or VZV capsids (G) were incubated with cytosol at ATP/GTP high for $1 \mathrm{~h}$ or the indicated time $(\mathrm{E}, \mathrm{F})$ at $37^{\circ} \mathrm{C}$, and classified into intact, punched and flat capsids by electron microscopy $(A-G)$, or the amount of released viral DNA was measured by qPCR (H). (A) Quantification of punched and flat D capsid shells in cytosol prepared from rested M $\phi$ or IFNinduced $M \phi_{\text {IFN }}$ macrophages, or from control A549 (mock) or A549-MxB(1-715) cells. (B) Increasing amounts of $\mathrm{MxB}(1-715)$ [\%] were added to control $\mathrm{A} 549$ cytosol, and the amount of punched and flat capsids were quantified after incubation in these mixtures. (C) Cytosols of A549 cells expressing $\mathrm{MxB}(1-715)$ and $\mathrm{Mx}(25-715)$ or $\mathrm{MxB}$ (1-715)-FLAG and $\mathrm{MxB}$ (26-715)-FLAG were incubated with antiFLAG antibodies coupled to magnetic beads, the flow-through fractions (FT) were harvested, capsids were treated with anti-FLAG treated or control cytosols, and the amount of punched and flat capsids 
were quantified. (D) Capsids were incubated in cytosols prepared from A549 cells expressing fulllength (FL) $\mathrm{MxB}(1-715), \mathrm{MxB}(26-715), \mathrm{MxB}(\mathrm{K} 131 \mathrm{~A}), \mathrm{MxB}(\mathrm{T} 151 \mathrm{~A})$, or $\mathrm{MxB}(\mathrm{M} 574 \mathrm{D})$ at $\mathrm{ATP} / \mathrm{GTP}^{\text {low }}$ or ATP/GTP ${ }^{\text {high }}$ levels. (E) Time-course of MxB-induced disassembly of capsids pre-adsorbed onto EM grids, incubated with cytosol from $A 549-\mathrm{MxB}(1-715)$. (F) Analysis of $D, V_{0.5}$, or $V_{0.1}$ capsids treated with $\mathrm{MxB}(1-175)$ cytosol for broken (punched + flat) capsids after negative stain and $\mathrm{EM}$ as described for panel E. (G) Quantification of MxB cytosol disassembly of D capsids of HSV-1(17 ${ }^{+}$Lox, HSV-1(KOS), or HSV-2(333), or nuclear C capsids of VZV, after incubation in cytosol from A549-MxB(1-715) cells. (H) D capsids were incubated with different cytosols for $1 \mathrm{~h}$ at $37^{\circ} \mathrm{C}$ or treated with $1 \%$ SDS and $10 \%$ Tx-100 only, and the released DNA not protected by capsid shells was quantified by qPCR. Error bars: SEM from 100 capsids in 3 biological replicates. One symbol of *or $\S$ denotes $p<0.05$, two $p<0.01$, and three $p<0.001$ as determined in One-way analysis of variance with a Bonferroni post-test, and comparing the relative amounts of $\left({ }^{*}\right)$ punched and $(\S)$ flat capsids, or indicating the differences with 1090

\begin{tabular}{|c|c|c|c|c|c|}
\hline Treatment & Cyt. & $\mathrm{MxB}$ & $\begin{array}{c}\text { MxB } \\
\mathrm{FT}\end{array}$ & $\begin{array}{l}\text { MxB } \\
- \text { FLAG }\end{array}$ & $\begin{array}{c}\text { MxB } \\
\text {-FLAG FT }\end{array}$ \\
\hline \multicolumn{6}{|l|}{$M \times B$} \\
\hline \multicolumn{6}{|l|}{ MxB-FLAG } \\
\hline GAPDH & $m$ & $=$ & & $=$ & \\
\hline
\end{tabular}

Supplementary Figure S7: Cytosol immunodepleted for MxB. Cytosols prepared from A549-MxB(1715) and $\mathrm{MxB}$ (26-715) expressing $\mathrm{MxB}(1-715)$ and $\mathrm{MxB}$ (26-715), or A549-MxB-FLAG cells expressing $M \times B(1-715)-F L A G$ and $M \times B(26-715)-F L A G$, respectively, were incubated with agarose beads coupled to anti-FLAG antibodies. After immunodepletion with anti-FLAG beads to deplete MxB(1-715)-FLAG and $M \times B(26-715)$-FLAG, the flow through (FT) was harvested. To determine to what extend the FLAGtagged MxB proteins had been depleted, the starting cytosols (MxB, Mxb-FLAG) as well as the respective $\mathrm{FT}$ fractions were probed by immunoblot using antibodies directed against MxB, FLAG, or GAPDH as a loading control.

Figure S7-source data 1,2. Full western blot images for the corresponding detail sections shown in 

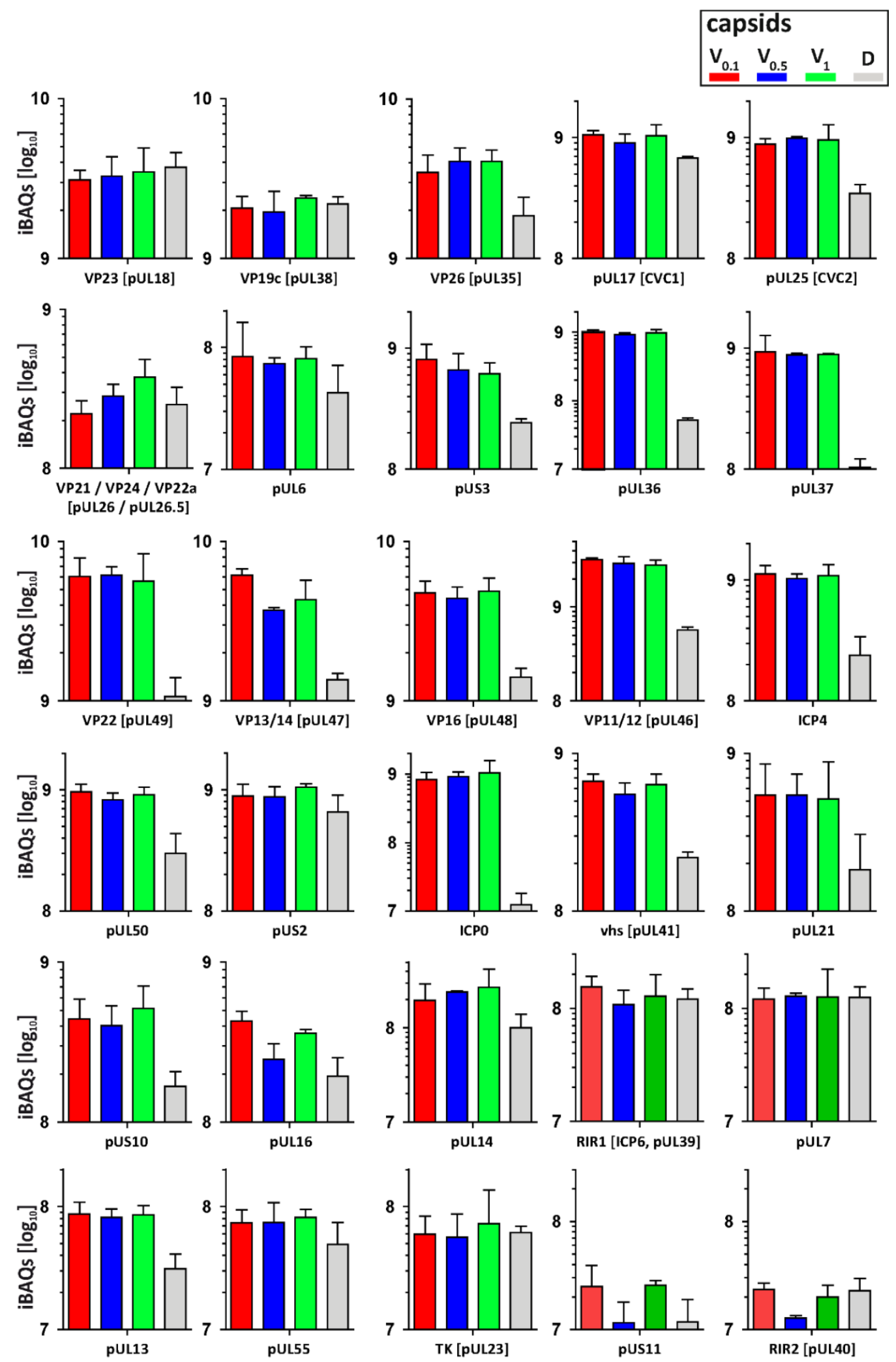

Figure 8: Structural and tegument characterization of $\mathrm{V}_{0.1}, \mathrm{~V}_{0.5}, \mathrm{~V}_{\mathbf{1}}$, and $\mathrm{D}$ capsids. The composition of HSV-1 $\left(17^{+}\right)$Lox derived $V_{0.1}$ (red), $V_{0.5}$ (blue), $V_{1}$ (green) and $D$ (grey) capsids was analysed by quantitative mass spectrometry in four biological replica. The sum of all the peptides intensities (iBAQ, intensity-based absolute quantification) of each viral protein known to participate in the structure of the capsids was normalized to the one of VP5 and displayed in a bar plot for each viral protein. 

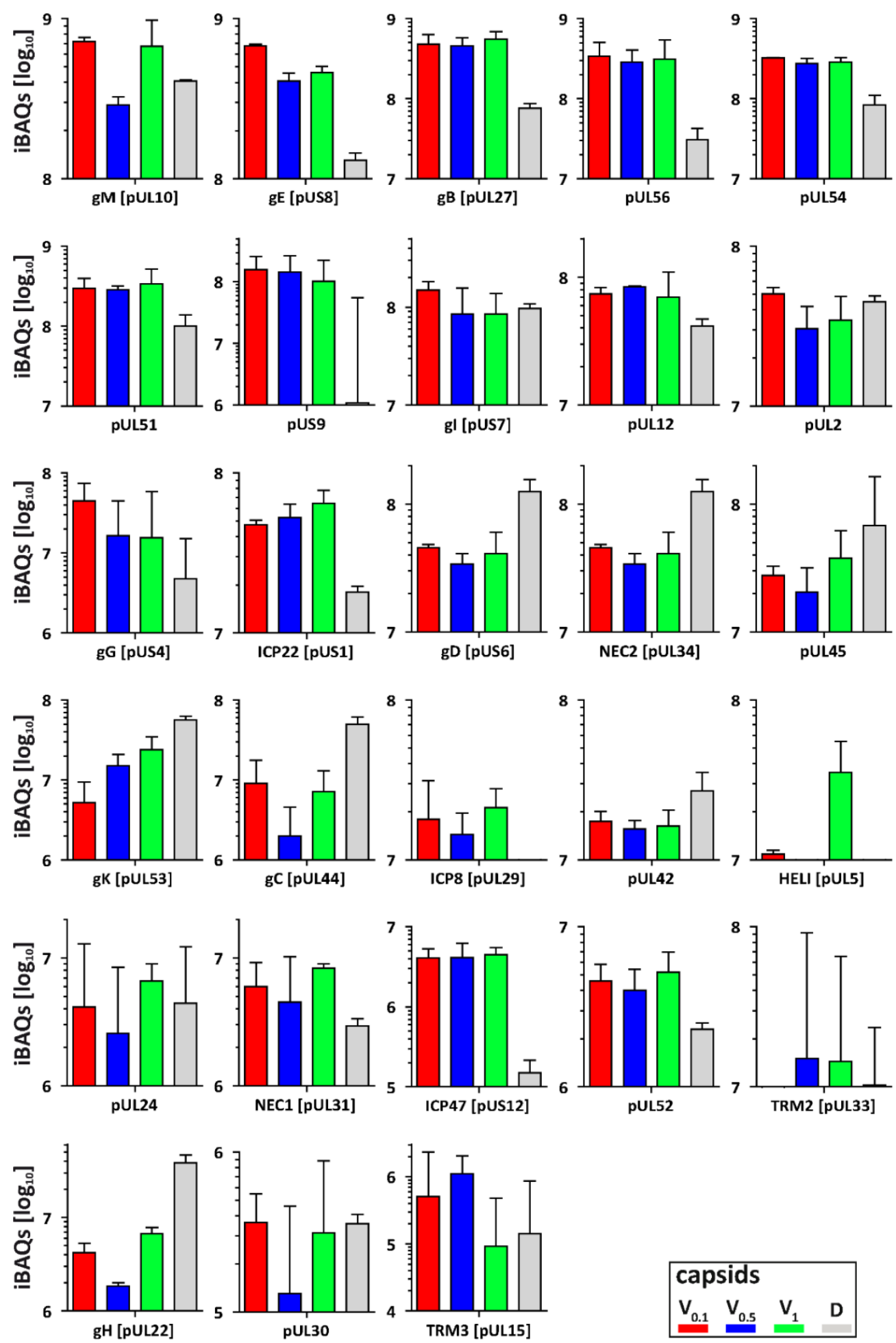

Supplementary Figure S8: Membrane and non-structural proteins on $V$ capsids versus $D$ capsids. The composition of HSV-1 derived $\mathrm{V}_{0.1}$ (red), $\mathrm{V}_{0.5}$ (blue), $\mathrm{V}_{1}$ (green) and $\mathrm{D}$ (grey) capsids were analysed by quantitative mass spectrometry in four biological replicates. The sum of all the peptides intensities (iBAQ, intensity-based absolute quantification) of each viral protein unknown to participate in the structure of the capsids was normalized to the one of VP5 and displayed in a bar plot 